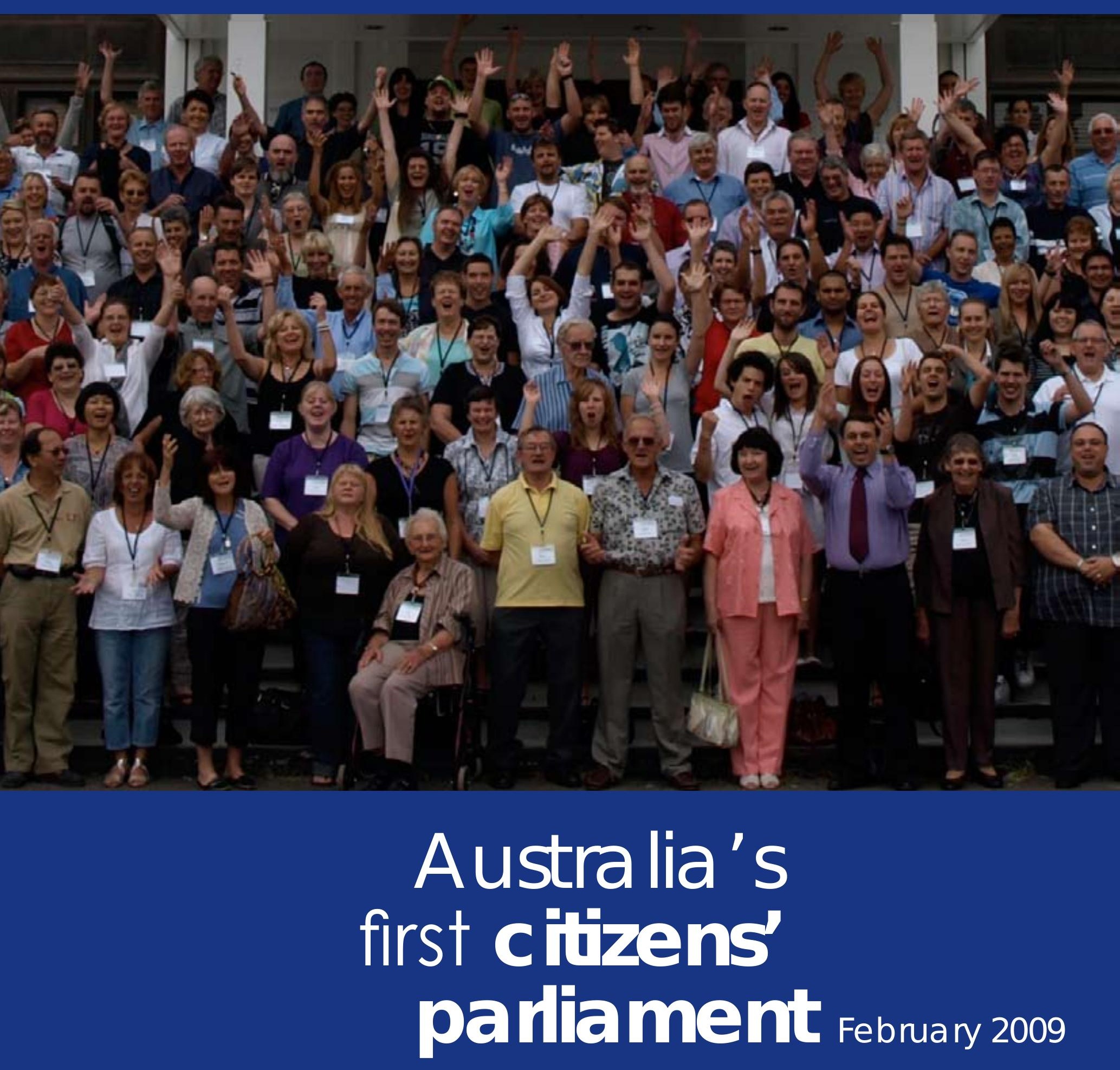


New Democracy:

Putting People Back into Politics

(C) 2009

Published by the newDemocracy Foundation

PO Box R418 Royal Exchange

NSW 1225 Australia

Web: www.newdemocracy.com.au

Email: administrator@newdemocracy.com.au

Phone: +61 290377293

Fax: +61 295695434

\section{SUPERVISING EDITOR}

Lyn Carson

\section{EDITOR AND CONTRIBUTING WRITER \\ Jesse Blackadder}

\section{ACKNOWLEDGEMENTS}

Material in this handbook has been drawn from numerous sources and organisations involved in the 2009 Citizens' Parliament.

\section{EDITORIAL INPUT has come from:}

Luca Belgiorno-Nettis, newDemocracy

Lyn Carson, University of Sydney John Dryzek, Australian National University

Kath Fisher, Southern Cross University

Max Hardy, Twyford Consulting

Janette Hartz-Karp, Curtin University of Technology

Kathy Jones, Kathy Jones Associates

Vickianne Lane, newDemocracy

Ron Lubensky, University of Sydney

Ian Marsh, University of Tasmania

Simon Niemeyer, Australian National University

Brian Sullivan, CivicEvolution

\section{PHOTOGRAPHS \\ Kaye Shumack and John Pacitto}

The 2009 Citizens' Parliament received funding through the Australian Research Council Linkage Projects Scheme. The Linkage Projects scheme supports collaborative research and development projects between higher education organisations and other organisations, including within industry, to enable the application of advanced knowledge to problems.

Citizens' Parliament - Puating people into pulitics

PO Box R418, Koyal Exchange NSW 1225 adminificitizenenarliament org su www citizenepurlument org ar 


\section{Australia's 2009 Citizens' Parliament}

A citizens' parliament involves a large group of randomly selected citizens (matching the demographics of the area they represent) coming together to listen, learn, reflect upon and discuss an issue of public importance. Through this transparent process of deliberation, they produce recommendations for those in leadership that reflect the considered views of the broader community.
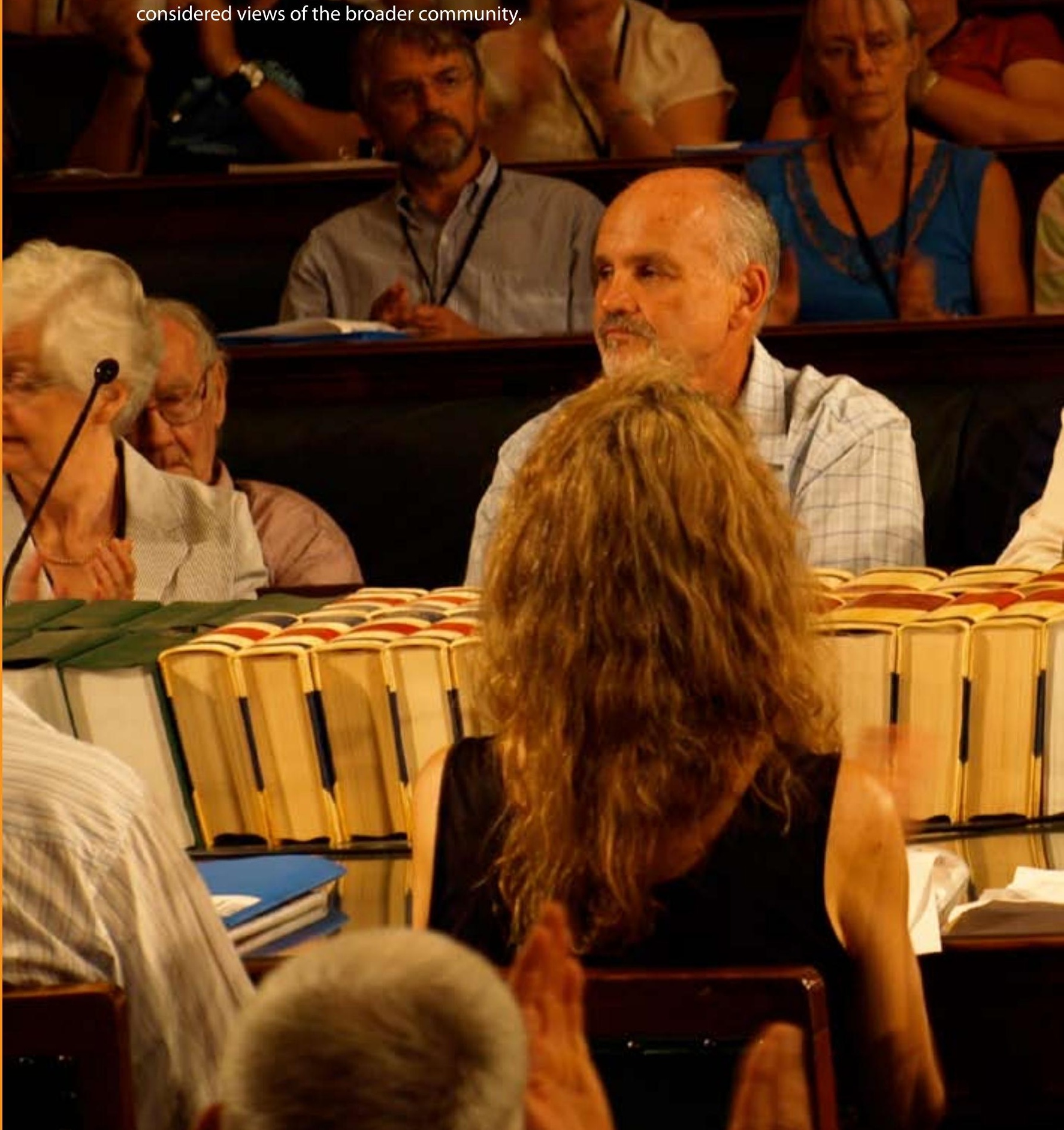
FOREWORD

. INTRODUCTION.

1.1 HOW TO USE THIS HANDBOOK

1.2 THE RESEARCH PROJECT.

WHAT IS DELIBERATIVE DEMOCRACY?

2.1 DELIBERATIVE DEMOCRACY ...............................................................................

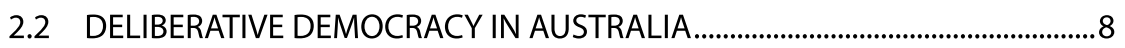

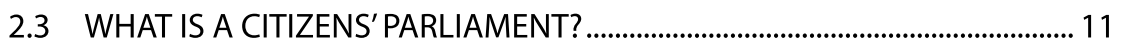

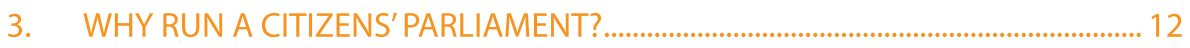

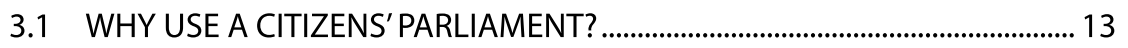

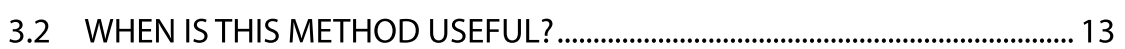

4. PLANNING FOR A SUCCESSFUL CITIZENS' PARLIAMENT ................................... 17

4.1 SETTING THE GOALS OF THE PROCESS ............................................................ 17

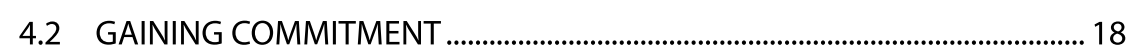

5. WHO IS INVOLVED IN A CITIZENS' PARLIAMENT? ........................................... 21

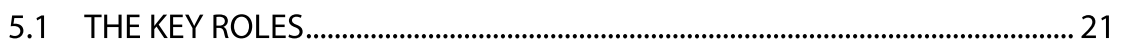

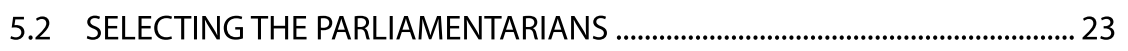

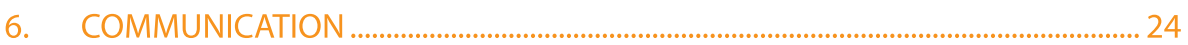

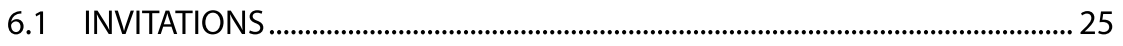

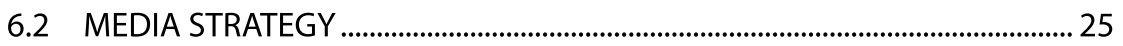

6.3 ELECTRONIC AND SOCIAL MEDIA ...................................................................... 25

7. HOW THE AUSTRALIAN CITIZENS' PARLIAMENT WORKED ................................ 26

7.1 SNAPSHOT: THE AUSTRALIAN CITIZENS' PARLIAMENT PROCESS ........... 27

7.2 DETAIL:WORLD CAFE EVENTS TO SET THE AGENDA.................................... 27

7.3 DETAIL: THE REGIONAL MEETINGS ........................................................................ 28

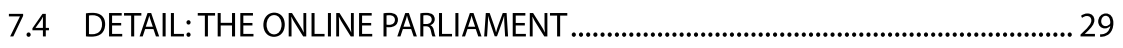

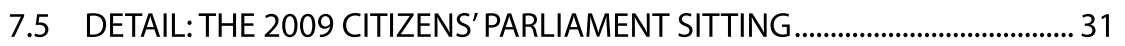

7.6 DAY ONE: UNDERSTANDING WHAT WE WANT TO ACHIEVE ....................... 32

7.7 DAY TWO: BROADENING OUR PERSPECTIVES ................................................... 33

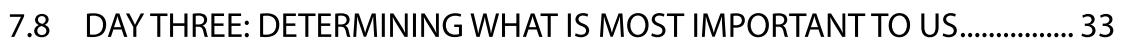

7.9 DAY FOUR: CONSOLIDATING AND DELIVERING

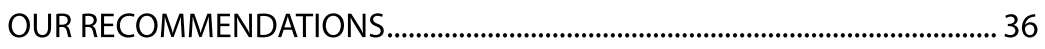

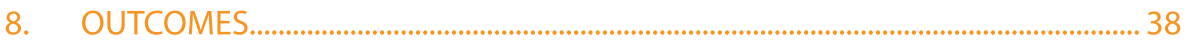

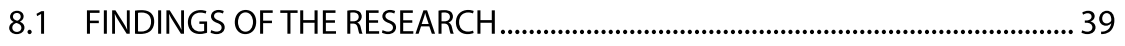

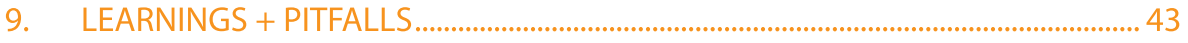

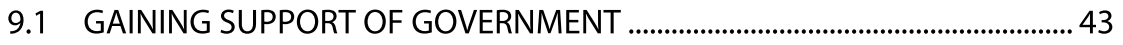

9.2 ELECTRONIC COMMUNICATION AND SOCIAL MEDIA ....................................43

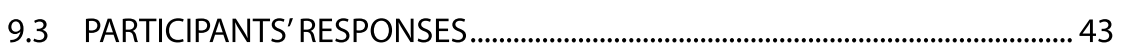

9.4 COMMENTS FROM CITIZEN PARLIAMENTARIANS ........................................... 44

10. THE FUTURE: POTENTIAL ROLES FOR CITIZENS' PARLIAMENTS ...................... 46

11. THE 2009 CITIZENS' PARLIAMENT CONVENORS........................................................ 48

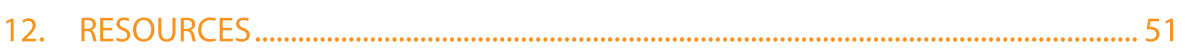

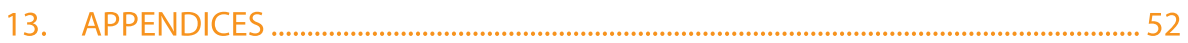




\section{FOREWORD}

Australia's first citizens' parliament was held at Old Parliament House in Canberra on 6-9 February 2009. One hundred and fifty people from across Australia spent four days discussing and deliberating our democracy and how it could be improved.

The 2009 Citizens' Parliament was an extraordinary forum. Australians not normally involved in the political process were able to contribute to discussion about how our governments work and review the strengths and weaknesses of our democratic system. Through personal experiences, varied opinion and the sharing of information, the citizen parliamentarians devised options for change. Their recommendations were put forward in the final report of the 2009 Citizens' Parliament.

This handbook is a tool for people interested in deliberative democracy. It shows step-by-step how the 2009 Citizens' Parliament was organised, referring to detailed appendices. By showing how the process of the 2009 Citizens' Parliament unfolded, it gives you, the reader, the flavour of this extraordinary event and the tools to organise other deliberative democracy programs.

Our congratulations go to all those on the organising team and the volunteers who assisted during the event. They encouraged and recorded the enthusiasm of the participating citizens through their own expertise, and excellent facilitation, organisation and research skills. We would also like to acknowledge and thank the participating citizens who gave up their time to participate and so generously shared their energy and ideas.

This handbook, plus the research outcomes that will be published in the future, will make an important contribution to the practice and theory of deliberative democracy.
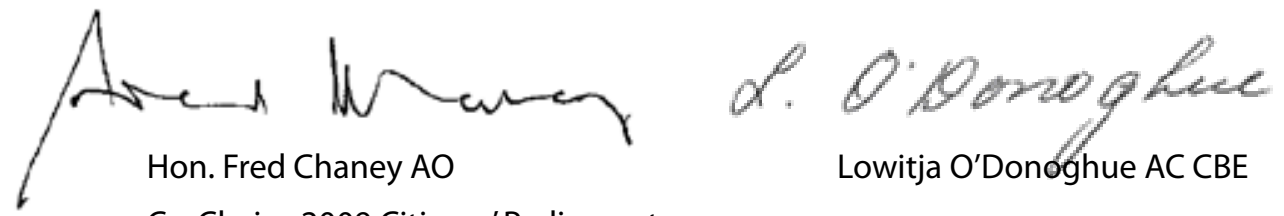

Co-Chairs, 2009 Citizens' Parliament 


\section{INTRODUCTION}

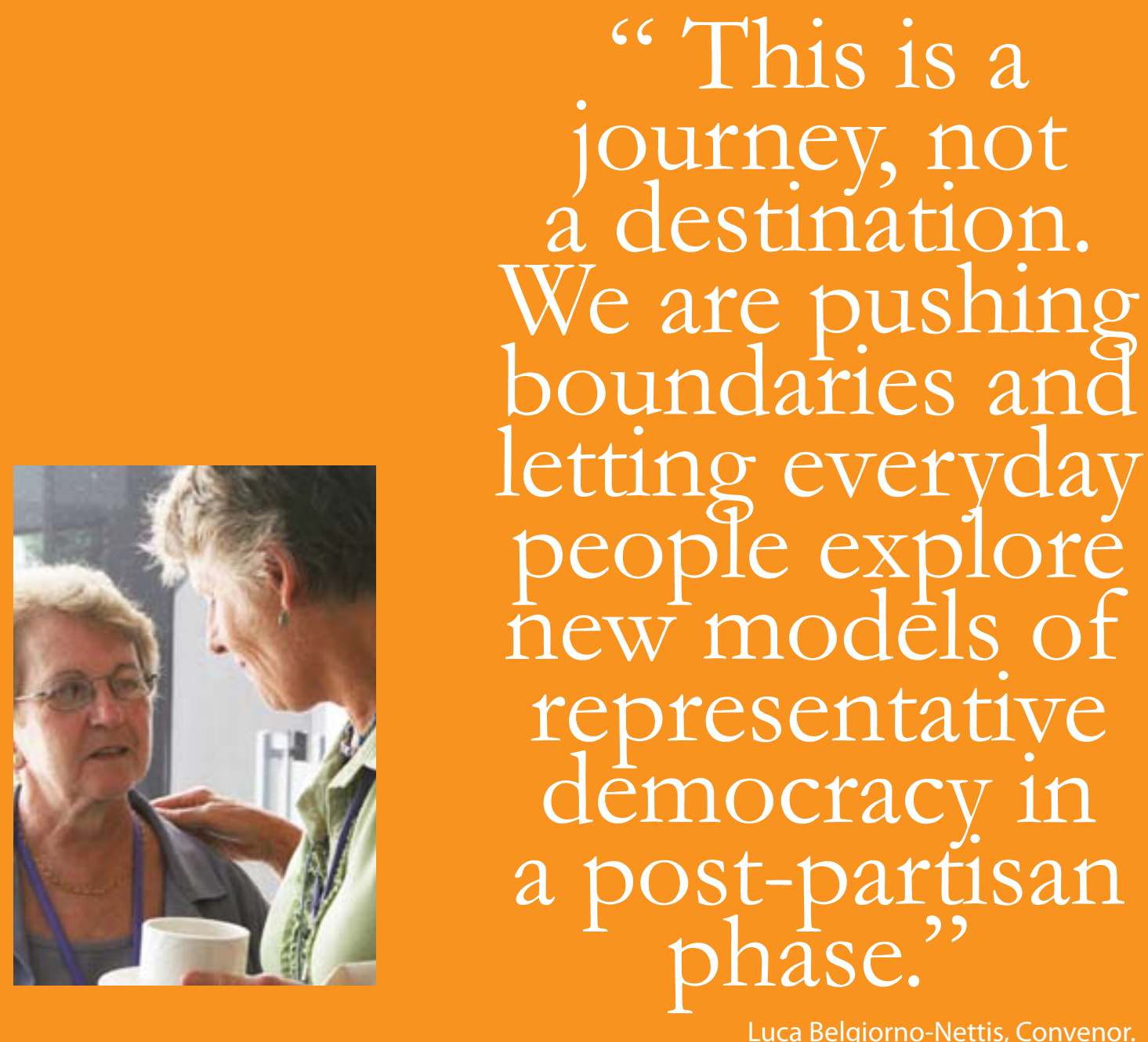




\section{INTRODUCTION}

A citizens' parliament involves a large group of randomly selected citizens (matching the demographics of the area they represent) coming together to listen, learn, reflect upon and discuss an issue of public importance. Through this transparent process of deliberation, they produce recommendations for those in leadership that reflect the considered views of the broader community.

The mission of deliberative processes like citizens' parliaments is to change the way people talk about politics and make political decisions. A citizens' parliament is a way of involving communities in decision making and planning and helping decision-makers deal with complex issues, while bypassing the problems associated with other approaches such as conventional questionnaires and public hearings.

A citizens' parliament is a way to find out how citizens think about an issue when presented with detailed information from differing viewpoints and given support to discuss it in a non-adversarial way. Through a citizens' parliament, people can participate in a meaningful way in public decisionmaking by providing direct, considered and well-informed feedback on key issues to those in leadership.

Australia's 2009 Citizens' Parliament was the first in the country. Its 150 participants deliberated on the question 'How can Australia's political system be strengthened to serve us better?' It was run by a research team of academics from three universities and the newDemocracy Foundation. The convenors intended not only to run the 2009 Citizens' Parliament, one of the most ambitious exercises in democratic participation ever attempted, but also to study the process and the outcomes.

The 2009 Citizens' Parliament functioned as a pilot, showing what is involved in running such an event and demonstrating to governments the potential for citizen involvement in decision-making. It continues to contribute to public understanding of Australia's institutions of government and to debates about possibilities for their reform. The project is illuminating more effective citizen participation and public consultation in Australia's democracy and adding to the growing, worldwide evidence that deliberating citizens can competently inform public policy.

\section{Recommendations from the 2009 Citizens' Parliament}

During the four days of deliberation for the Citizens' Parliament, over 50 ideas were considered that could bring about the political system that the citizens wished to leave to the next generation. Eventually the following six proposals surfaced as those with most support:

1. Reduce duplication between levels of government by harmonizing laws across state boundaries.

2. Empower citizens to participate in politics through education.

3. Accountability regarding political promises and procedure for redress.

4. Empower citizens to participate in politics through community engagement.

5. Change the electoral system to optional preferential voting.

6. Youth engagement in politics.

They were presented to the Prime Minister's representative, the Hon. Anthony Byrne, Parliamentary Secretary to the Prime Minister, on the final day of deliberations.

"Our citizens'

parliament is a world

pioneer, first because

it is national and

based on one person

from each electorate,

second because of the

'Online Parliament'

component, third -

and most important

- because we put

agenda creation in the

hands of the citizens

themselves.

"We did of course give them a broad charge

- 'how can Australia's

system of government

be strengthened to

serve us better?' - but

within this they were

free to craft options of

their own. And they

did.

Professor John Dryzek, Convenor.

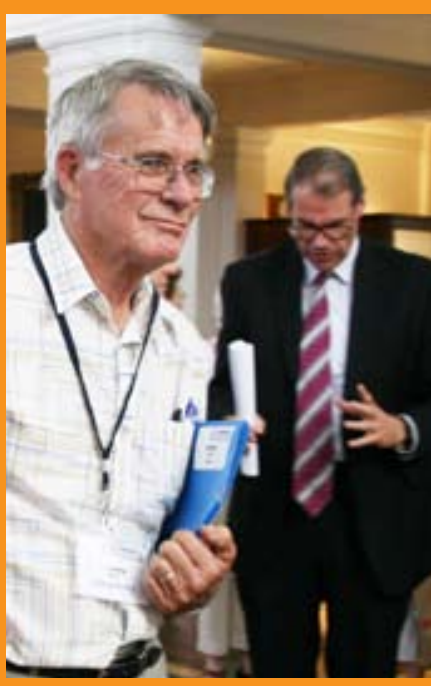


"When we ask

Australians what

they think about

something, we tend to

do it firstly in a fairly

superficial way and

secondly in a way that

the usual suspects

come forward: people

who are passionate

about an issue and

who have worked long

and hard advocating

for it.

"It's actually

remarkably difficult

to find out what

a microcosm of

Australians think and

that's the idea behind

the 2009 Citizens'

Parliament, to include

people who are rarely

heard from."

Associate Professor Lyn

Carson, Convenor.

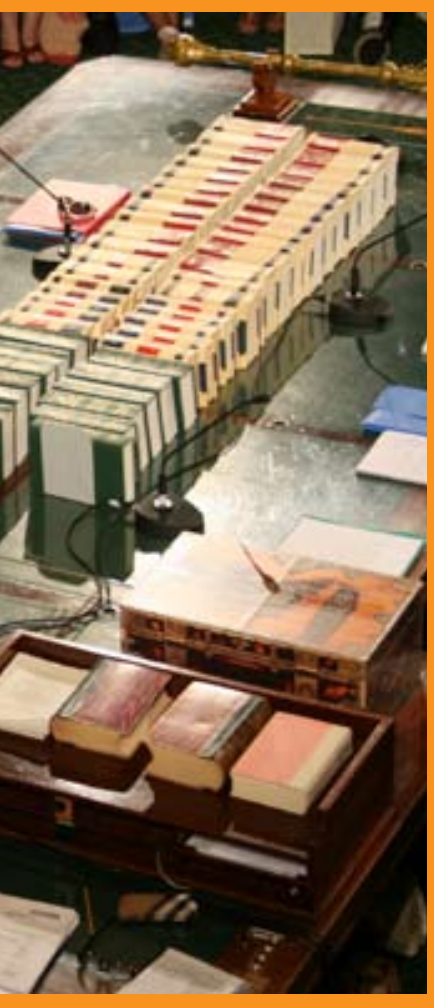

\subsection{HOW TO USE THIS HANDBOOK}

This handbook is both a record of the 2009 Citizens' Parliament and a blueprint for those wanting to organise their own citizens' parliament or similar deliberative process. It outlines the steps involved in running a citizens' parliament and illustrates how it works in a real life situation. It draws on many of the principles and procedures common to deliberative methods, while focusing on one particular method and how it can provide informed and considered public opinion in an unbiased and transparent manner.

The specific organisational processes are included as downloadable appendices for readers needing that level of detail. They can be downloaded from www.newdemocracy.com.au.

\subsection{THE RESEARCH PROJECT}

The 2009 Citizens' Parliament was run by a research team of academics from the Australian National University, the University of Sydney and Curtin University of Technology in partnership with the newDemocracy Foundation. The convenors were all experts in deliberative theory and practice. The project was funded by the Australian Research Council and the newDemocracy Foundation.

For more information about the team of conveners please see Section 11 The 2009 Citizens' Parliament Conveners.

It is rare for large-scale initiatives of deliberative democracy to take place, as they can be costly and involve a great deal of organisation. Smallerscale processes like citizens' juries have received a lot of research attention, but more evidence is required to demonstrate what happens when those methods are scaled up. Running the 2009 Citizens' Parliament provided such an opportunity. The information gathered during the 2009 Citizens' Parliament (with the consent of all participants) is answering current research questions and will be available to answer new questions that may arise in the years ahead. 


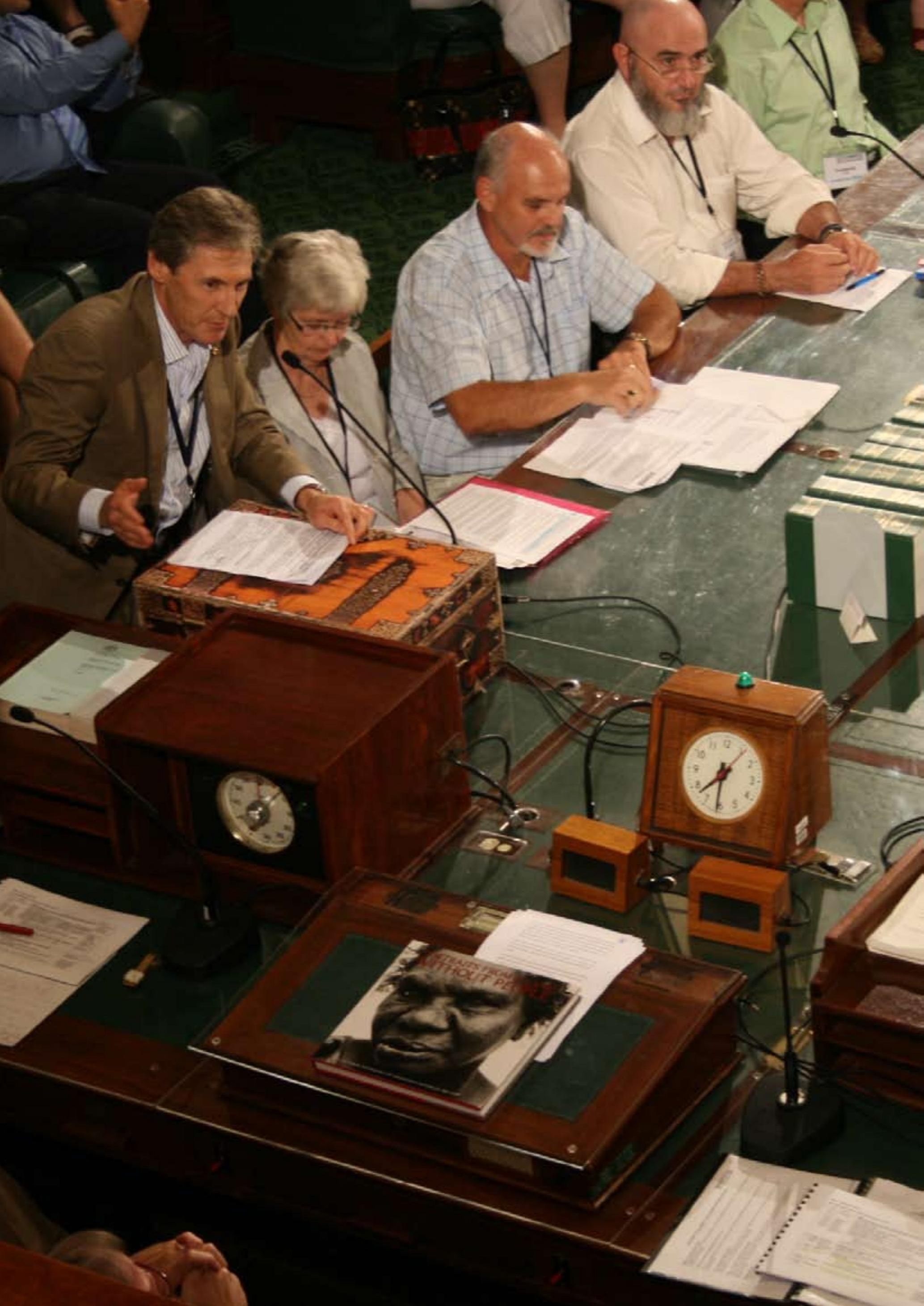


WHAT IS DELIBERATIVE DEMOCRACY?
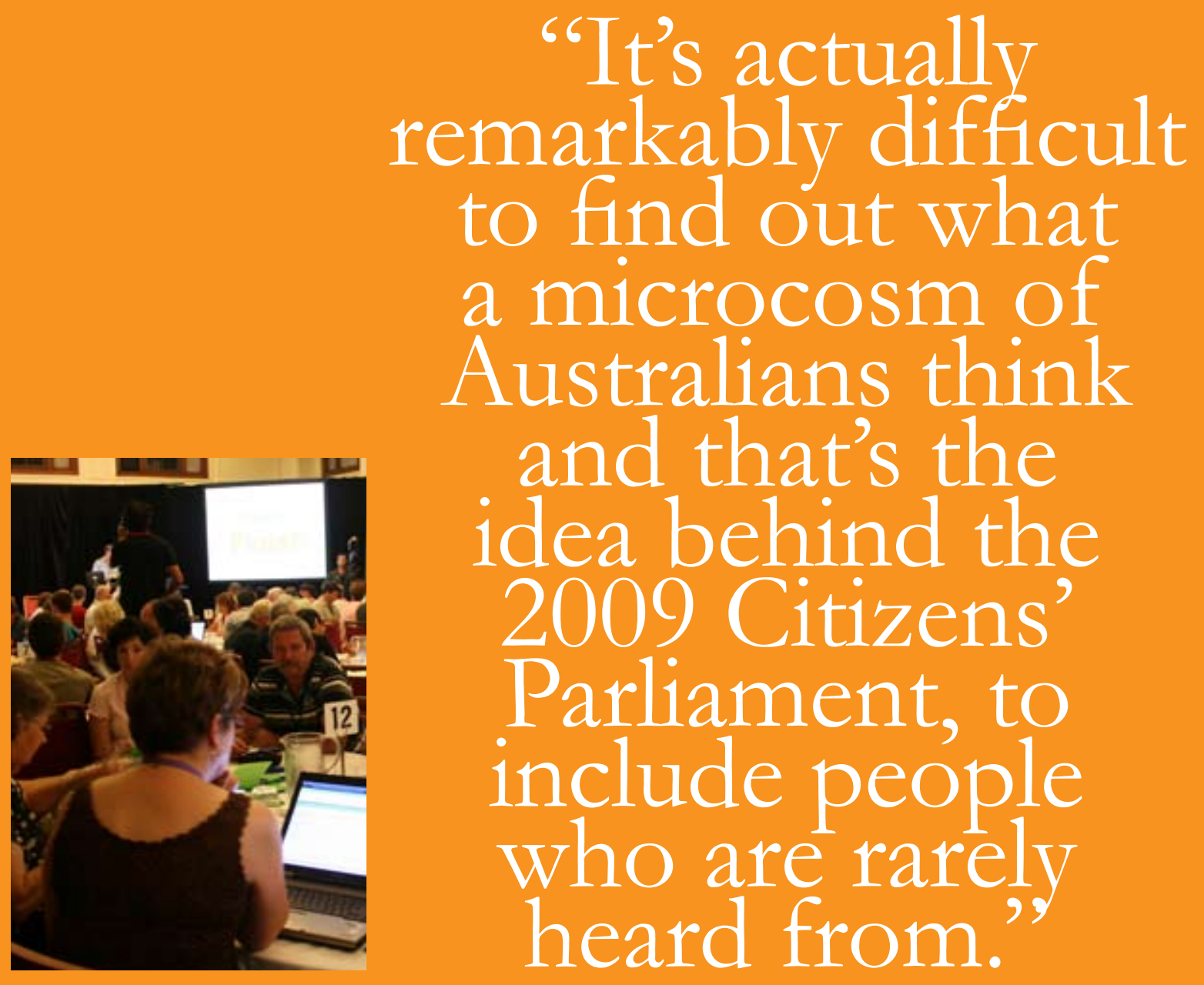

Associate Professor Lyn Carson, Convenor. 


\subsection{DELIBERATIVE DEMOCRACY}

There are various ways for citizens to participate in democracy. In Australia's representative system, citizens vote for individuals to represent them in legislatures, to make decisions on their behalf. When they vote in a referendum, they are participating in direct democracy. Many people become involved in activist groups and other organisations that are referred to as civil society, which promote social, economic and environmental change from outside of government.

In many policy-setting situations in Australia and overseas, groups of citizens committed to working together civilly and constructively have demonstrated a capacity to engage with policy experts and legislators and to learn, innovate and recommend solutions that satisfy the needs of their communities. This is an example of deliberative democracy, which brings citizens and policy-makers together to solve difficult problems.

The deliberative approach engages a group in a respectful and inquiring conversation to explore a problem, understand issues from diverse perspectives and uncover common ground. Deliberation is usually facilitated by a professional who is neutral, helps disentangle disagreements and keeps the process moving forward. Individuals are free to hold their positions or explore alternatives while contributing to dialogue on an equal basis.

Deliberative democracy forums or processes involve selecting ordinary citizens from the entire population. The selection, while random, needs to balance gender and match age, education and other relevant factors to the distributions revealed by census statistics. This microcosm is often called a mini-public.

The scale of deliberative democracy processes can vary dramatically depending on their purpose. Large processes include deliberative opinion polls, citizens' parliaments, consensus conferences and citizens' assemblies, while citizens' juries are at the small end of the scale.

For a local issue, a citizens' jury comprising 12-25 randomly selected individuals is a suitable size. For a national issue, a citizens' parliament or citizens' assembly of several hundred may be required.

For a more detailed overview of deliberative democracy methods see the Ideas for Community Consultation booklet ${ }^{1}$ and:

Appendix 1. What is deliberative democracy? topic sheet.

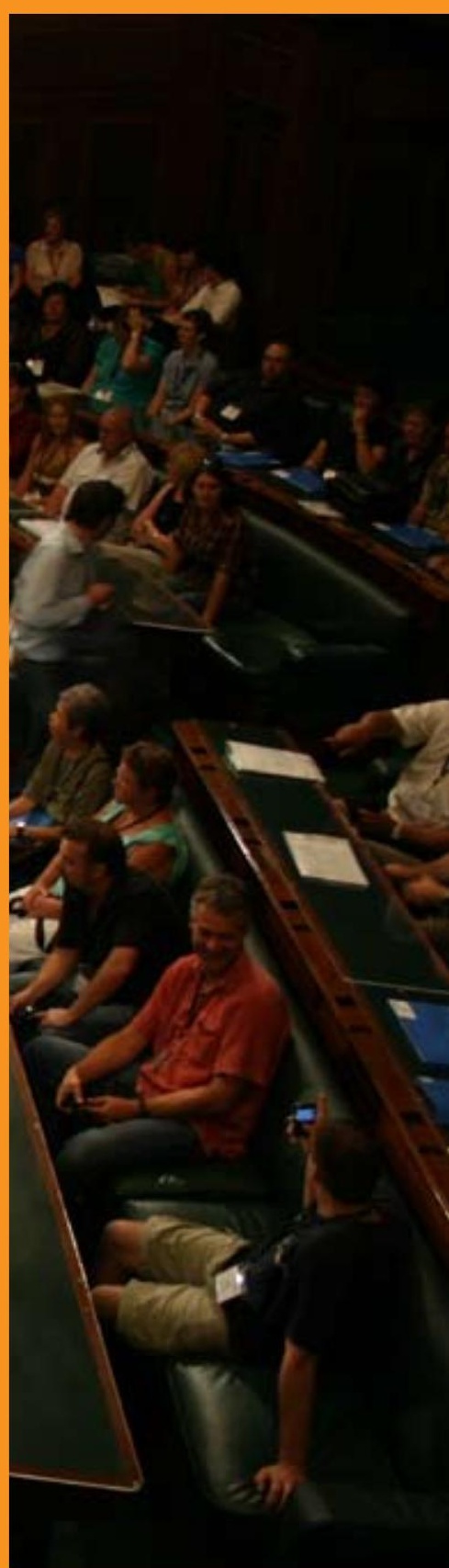

\section{DELIBERATIVE DEMOCRACY IN BRITISH COLUMBIA}

In 2001 the Premier of the Canadian province of British Columbia, Gordon Campbell, promised that if elected, his government would call a citizens' assembly on electoral reform. When the assembly was created in 2004 it was the first time in the world that randomly selected citizens had been given such power to influence the electoral process. The assembly was unanimously endorsed by the parties in the legislature, and parties and community leaders outside it. Its mandate was to look at how votes cast in provincial elections translated into seats in the legislature.

One hundred and sixty randomly selected citizens participated in an in-depth process which included learning about electoral systems (from

1 Downloadable at www.activedemocracy.net/articles/ principles_procedures_final.pdf 


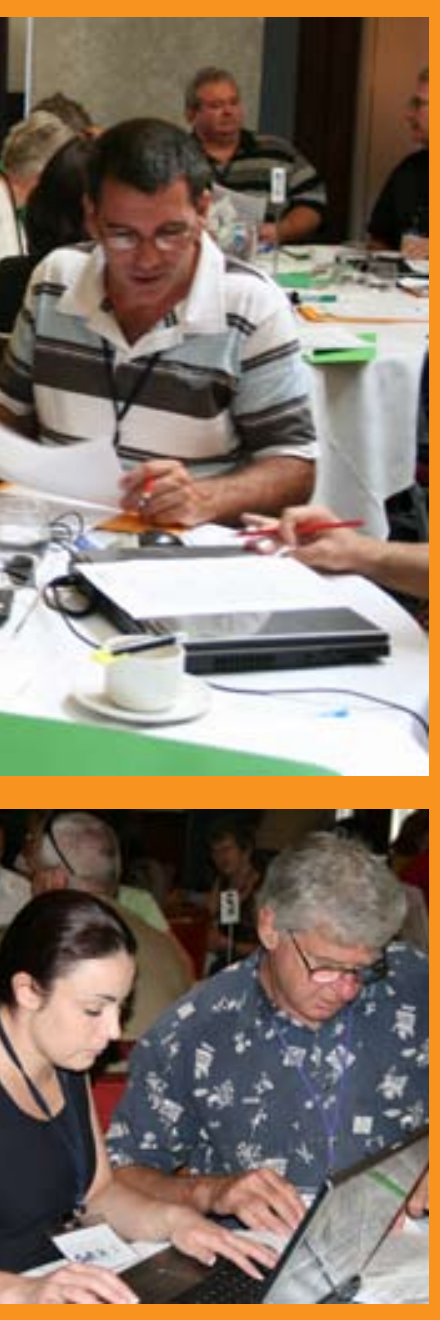

January-March 2004), public hearings (May-June) and deliberation (September-November). The assembly's final report recommended replacing the province's first past the post system with a single transferable vote system. When the proposal was put to a referendum, it had to be approved by $60 \%$ of voters nationwide and it needed to gain a simple majority in at least $60 \%$ of Canada's 79 districts. The national "yes" vote was $57.7 \%$ - just short of was required, although the proposal did have majority support in 77 districts $^{2}$.

\subsection{DELIBERATIVE DEMOCRACY IN AUSTRALIA}

Some of the world's most important and influential deliberative processes involving ordinary citizens have been held in Australia, such as the NSW Climate Summit and Perth's 'Dialogue with the City'.

\section{PERTH'S 'DIALOGUE WITH THE CITY'}

'Dialogue with the City', held in Perth in 2003, strongly influenced the West Australian Government's policy on city planning. The process brought more than 1100 residents of Perth together to help make decisions that would guide the development of the city and its surrounds for the next 30 years. The process involved a survey of 8000 residents to gauge community attitudes; online discussion groups; an art and essay competition for school children; and a major information campaign. The Dialogue team held sessions with youth, Aboriginal people and people whose first language is not English.

Eight hundred community participants reflected the district's demographic profile in age, gender and geographical location, as well as covering a broad range of community interest groups. After a day of deliberation, the participants identified their preferences for Perth in the future. Their input fed into the Network City strategy for Perth ${ }^{3}$.

\section{WESTERN AUSTRALIA'S ROAD TRAIN SUMMIT}

Following considerable community concern over long vehicles and road trains in metropolitan areas, in 2001 the state government called the Road Train Summit to deliberate on the issue. It involved consensus forums in metropolitan Perth, Katanning, Kalgoorlie and Geraldton.

Considerable effort was made to ensure all stakeholders in the road train debate were fairly represented. Just under 100 participants attended each forum, with stakeholders represented at each small table. Members of parliament - Labor, Liberal and Greens - facilitated at each table, together with CEOs of the state government departments involved and their executive teams.

Community groups, industry groups, local councils and the state government developed background papers and circulated them to participants prior to each forum. Participants listened to short presentations from the authors, added information from the floor and asked questions of the panels. Dialogue at the tables began with a process of empathetic

2 For more information see www.citizensassembly.bc.ca

3 For more information see www.dpi.wa.gov.au/annualreport0304/2276.asp 
listening, where each stakeholder's point of view needed to be thoroughly understood. The key issues to be resolved were determined at a plenary session. Prioritised consensus options were taken to the next forum to determine the extent of state-wide consensus.

All the consensus options were referred on to a Planning Implementation Team of community, industry, state and local government representatives. This team worked for several months to translate the options into actions. Over the next two years, all participants received quarterly feedback newsletters outlining the progress made against each action target. At the end of two years, each action agenda in the Final Report was put into effect ${ }^{4}$.

\section{THE NSW CLIMATE SUMMIT}

On 19-21 February 2009, 80 members of the NSW community gathered at Redfern Town Hall, Sydney, for the NSW Community Climate Summit to develop recommendations on how citizens of NSW can work together to respond to climate change, for consideration in the development of the NSW Government's Climate Change Action Plan. The summit was the culmination of the NSW Climate Consensus Project, an initiative of the Nature Conservation Council of NSW and funded by the NSW Environmental Trust $^{5}$.

Utilising the deliberative democracy approach, summit participants were everyday citizens from across NSW who closely matched the NSW community demographic in relation to age, gender and residential location in NSW (city, inner regional or outer regional), and who came from a variety of backgrounds, professions and interests.

Summit participants heard from a range of expert speakers, engaged in interactive panel sessions and undertook a number of small group deliberations to arrive at a set of recommendations focusing on the key priority areas of energy, transport, education, health, employment and training, land use and planning, social justice, waste and water, biodiversity and land management, and the building industry ${ }^{6}$.

\section{QUEENSLAND YOUTH JURY}

Citizens'juries have been so named because of their organisational similarity with legal juries, where a small number of randomly-selected citizens, reflecting a cross section of the public, comes to a decision. Unlike legal juries, citizens'juries are not adversarial and do not rely on a consensus among members. Rather than finding a verdict, the jury proposes a series of recommendations in response to a question (or 'charge') after a period of deliberation.

The Queensland Youth Jury was sponsored by a committee of the Queensland Parliament in February 2006. Twelve young people aged 16-21 deliberated over three days (after a day of preparation with the facilitator) on the charge 'How can democracy better serve young people in Queensland?' The young people were recruited through randomly distributing 2000 brochures in Queen St Mall as well as specifically inviting an Indigenous young person and a person with a disability.

4 For more information see http://www.21stcenturydialogue.com/index.php?package=Initiati ves\&action=Link\&file=road_train_summit.html

5 Executive Summary, NSW Community Climate Summit.

6 For more information see http://www.nccnsw.org.au/index.php?option=com_content\&task $=$ blogsection\&id=38\&ltemid $=1112$ 
"Will it change anything? It depends

on the quality of

what the citizen

parliamentarians

produce and people

in government seeing

this as enabling them

to govern better."

Fred Chaney, Citizens'

Parliament

Co-chairperson.
Panels of expert witnesses gave presentations, then the young people deliberated with the facilitator on questions they wanted to ask and discussions followed with the experts. The jury came up with 12 recommendations which they presented to members of the committee and other interested parties at Parliament House. Recommendations to Parliament on how young people could be better served by democracy were formally tabled in April 2006.

\section{AIRIES INLET CITIZENS' JURY}

In 2007 staff at Surfcoast Shire Victoria had recommended a plan by a civil engineering firm for a design of road, drainage and pathway capital improvements across the shire that would have cost ratepayers several million dollars. While many in the community wanted the improvements, others preferred the informal ambience of unsealed roads and open drains.

The council convened a citizens' jury to make an informed recommendation for the Airies Inlet precinct. A randomly selected jury of residents spent two days learning about the problems and the improvement options from experts and stakeholders. After a day of deliberation, the jury recommended a minimal set of improvements to address particular problems, but rejected the bulk of the plan. While this was not unexpected, the inclusive and deliberative nature of the process left no doubt that the recommendation reflected broad community sentiment. The evidence-based approach of the recommendations showed the resolve of the jury to remain respectful and objective in their analysis. Council had made a commitment at the start to act on the recommendations, and did $\mathrm{so}^{7}$.

\section{THE REID HIGHWAY EXTENSION CITIZENS' JURY}

The proposed traffic flow on the new Reid Highway Extension was a highly contentious issue in the Karrinyup/Carine community. When Labor came to government, the new Minister decided to consult the community about what it thought was the best option to trial.

The Reid Highway Extension Citizens' Jury was chosen from a random sample of 250 residents from the surrounding area (selected randomly by the WA Electoral Commission) who were invited to participate. Forty residents responded to invitations and 12 were chosen according to geography to ensure each key area was represented.

A week before the formal jury sitting, the jurors met with the Minister to hear about the process and receive a synopsis of the 152 community submissions to the jury, together with papers from Main Roads WA and Stirling Council.

The relevant action groups and other interested parties attended the jury deliberations as 'expert witnesses', to make factual presentations of their positions. After the presentations and discussion of the data, the jury deliberated. Technical experts remained to answer questions when needed.

The decision was unanimous: to fully open the Everingham/Reid intersection, with a series of measures to ensure the safety of the school community and residents. After such an extensive controversy, the community received the outcome with remarkable acceptance. The option was trialled using the methodology suggested by the jurors. The trial was successful and the road option recommended by the jury has now been built ${ }^{8}$.

7 For more information see http://www.surfcoast.vic.gov.au/Infrastructure/Documents/ Aireys_Inlet/CitizensJurylnfo.pdf

8 http://www.21stcenturydialogue.com/index.php?package=Initiatives\&action=Link\&file=re id_hwy_extension.html 
In all these designs it is ordinary citizens who do the deliberating and make recommendations - though they hear presentations from experts and advocates on different sides of an issue.

Although these processes differ in scale and in some of the details, what they have in common is the philosophy of random selection which matches the demographic of the community, and the practice of facilitated, informed deliberation.

\subsection{WHAT IS A CITIZENS' PARLIAMENT?}

To recap: a citizens' parliament is a large-scale deliberative democracy process, suitable for considering issues of state and national significance. It involves a relatively large group of randomly selected citizens (matching the demographics of the area they represent) coming together to listen, learn, reflect upon and discuss an issue of public importance. Through this transparent process of deliberation, the participants produce recommendations for those in leadership that broadly reflect the considered views of the broader community.

The citizens' parliament model used for this project:

- brings together a significantly sized group (150 individuals) of randomly chosen citizens who match a profile of the community at large using selected criteria;

- orients them to the program through preparatory local meetings;

- provides an online deliberation platform in the lead up to the parliament;

- encourages participants to call on friends and family for assistance in their preparation and to use information sources including the Internet, or local public library;

- brings them physically together in the parliament, where participants consider how best to deal with an issue of public importance;

- takes place over a number of days during which the parliament is given detailed balanced information about the issue and when members may challenge what's provided and seek out any additional information they want;

- has neutral facilitators who support the parliament by managing group dynamics to ensure that everyone has a fair say, the panel gets the information it needs and that it fulfils its terms of reference;

- has a chair to oversee the process;

- deliberates in a variety of formats such as small group discussion, brainstorming and full panel discussion; and

- concludes with the panel preparing a report which records its recommendations and any dissenting points of view.

Australia's 2009 Citizens' Parliament used a process based on the '21st Century Town Meeting' model developed by the AmericaSpeaks Foundation ${ }^{9}$, which involves using communications technology to synthesise the deliberations of large numbers of participants.
"In agreeing to

participate, you

become a member

of the 150 randomly-

selected Citizens

Parliament that will

convene in Canberra

on February 6 to

February 9, 2009 to talk

about the strengths

and weaknesses

of Australian

democracy. Together,

you will make

recommendations

about what might

be done to improve

matters. We expect

a plurality of views

to emerge. Your

recommendations

can then be deployed

to influence future

institutional and

legislative design. ..

...During the

Citizens' Parliament

you will be invited to

contribute to small-

group and plenary

discussions through

a range of formats

that encourage

open, respectful and

inclusive dialogue.

Your activity will be

guided by professional

facilitation. No

particular expertise

is required on your

part-it's your

everyday lived

experience as a citizen

that is most valued."

Citizens' Parliament

participant

information statement.

9 www.americaspeaks.org 


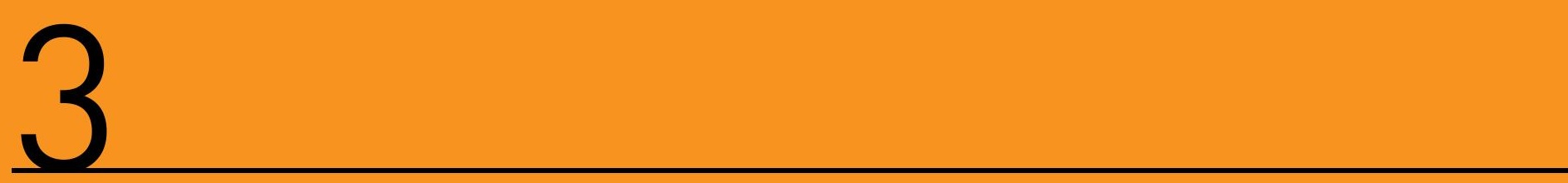

\section{WHY RUN A CITIZENS' PARLIAMENT?}

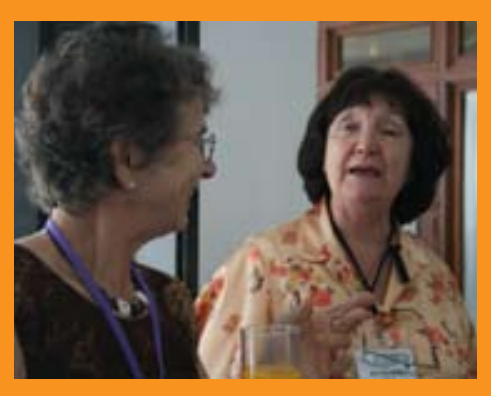

"Someone once said if you educate the mothers you educate the nation and it's true because we nurture the children and spend time with
them."

Mun Yee Goh, Citizen Parliamentarian. 


\subsection{WHY USE A CITIZENS' PARLIAMENT?}

Elected representatives are in a position which makes it difficult for them to accurately judge and act upon community values. They can be polarised by ideological debates, find it hard to identify community concerns and values and be pushed into one 'side' or another due to the adversarial nature of political debate. As well meaning as they may be, politicians, bureaucrats, stakeholders, advisors, and experts may not frame problems in ways that meet the needs of citizens.

Most governments don't go beyond consultation. Citizens get heard in hearings, requests for submissions or town meetings, but rarely is there real dialogue. Most people think heated debate and argument is the only way to solve problems, but this can create winners and losers and put people off politics altogether.

In contrast, deliberative democracy shifts some of the decision-making power to a mini-public, making participants into partners in the process. Citizens are engaged earlier and more deeply in the issue.

The deliberative process of a citizens' parliament involves rational, reasoned discussion with a cross-section of an entire population and uses various methods of inquiry such as directly questioning experts. It is not adversarial, although disagreement is inevitable and is valuable. A citizens' parliament values creativity and tends to build consensus rather than creating winning and losing sides.

Deliberative processes are not meant to replace representative or direct democracy, but to enhance and support it.

\subsection{WHEN IS THIS METHOD USEFUL?}

A citizens' parliament is useful when the questions to be deliberated over are relatively clear in advance. It is ideally suited to situations that involve complex issues, where expert involvement is required for participants to fully understand the process. Other indications that a citizens' parliament will be useful are when there are competing vested interests, when there are high stakes in the outcome, where decisions made will have an impact on the broader community, where there is scientific uncertainty (i.e. not a single generally accepted scientific opinion) and where there are high levels of risk involved. For citizens' parliaments to be effective tools of participation, there should be strong links back to the decision-making body.

\section{THE ADVANTAGES OF A CITIZENS' PARLIAMENT}

Public meetings can become dominated by well-organised interest groups or by more articulate and highly motivated individuals. In such situations, the voice of the average citizen is either not heard or excluded, or they themselves do not believe they can add value to public participation processes. Citizens' parliaments are a way of providing a transparent process for involving and bringing together experts, typical citizens, service providers, interest groups and the decision makers. Citizens' parliaments also emphasise deliberation and interaction. These attributes encourage learning and relationships amongst participants and officials.

Citizens' parliaments allow for the inclusion of expanded levels of expertise including non-traditional forms of knowledge and skills in the deliberative process. This works because the participant group is smaller

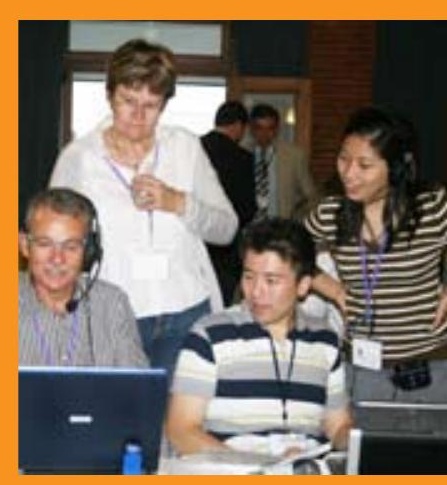

"A lot of participants have said this is the experience of a lifetime and that's the case for me.

"I myself have been empowered to know that I can do something... I'm leaving with the desire that I don't want this to end here. I want it to be a new beginning. Something that I can bring back and pass on to my family.

"Someone once said if you educate the mothers you educate the nation and it's true because we nurture the children and spend time with them."

Mun Yee Goh, Citizen Parliamentarian. 
"Public deliberation

is based on the

belief that everyone

has something to

contribute to a

conversation and

we need to do more

than just have a

conversation. We

need to weigh up

the pros and cons of

a range of options,

we need to crate the

space for new ideas

to emerge, we need

to ensure that the

people who are having

the deliberation are

very informed. Once

those things happen,

through deliberation

the participants can

begin to find common

ground. It's not

essential they reach

consensus, but they

explore the extent

to which they have

consensus. It's much

more than just a

conversation."'

Associate Professor Lyn

Carson, Convenor. and deliberations can be in-depth and investigative over a period of time.

Because the participants decide on recommendations in the final stage, the results of a community consultation process are tangible.

\section{THE LIMITATIONS OF A CITIZENS' PARLIAMENT}

It takes a high level of funding to run such an event, and an obvious limitation of a citizens' parliament is the cost of bringing together a large group of people for several days. Other risks or limitations include not gaining the cooperation and attendance of critical people and groups, not gaining the cooperation of the relevant decision-makers, and the difficulty of evaluating the influence of citizens' parliaments on decision-making.
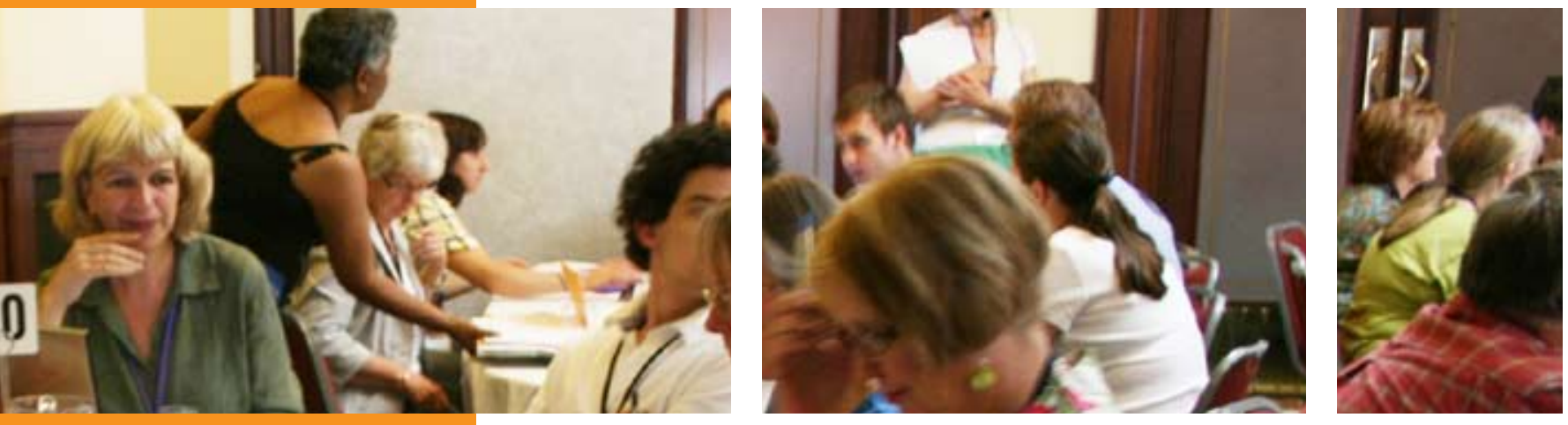


\section{4}

PLANNING FOR

A SUCCESSFUL

CITIZENS' PARLIAMENT
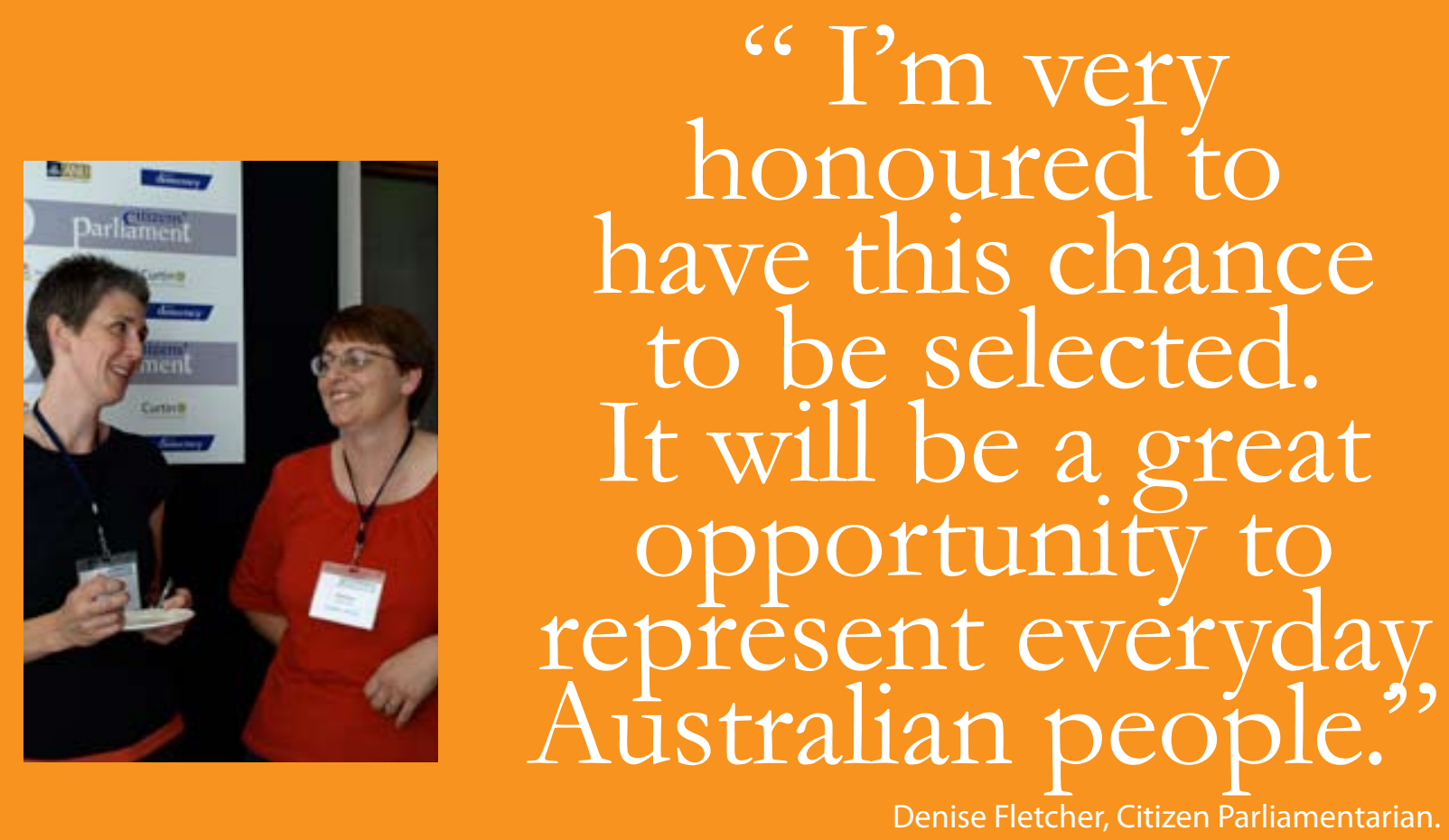


\section{PLANNING FOR A SUCCESSFUL CITIZENS' PARLIAMENT}

A successful citizens' parliament, like any major event, requires good planning, an adequate budget, clear goals and ideally the commitment of the ultimate decision-making authority to take on board the outcomes and recommendations.

While the 2009 Citizens' Parliament organisers had all been involved in deliberative democracy events before, for some this was their first large scale event. Organising it involved the additional challenges posed by a vast continent with a widely dispersed population. In planning Australia's first citizens' parliament, the convenors were piloting many of the processes, practices and technologies. The intention was to trial and observe the entire process and draw out important learning for the future of deliberative democracy.

\subsection{SETTING THE GOALS OF THE PROCESS}

When planning a citizens' parliament, convenors need to consider what they hope to achieve through the process, as planning decisions will flow from that point. SMART (Specific, Measurable, Achievable, Realistic and Time Specific) objectives are useful, and having a clear desired outcome is an important part of gaining the support of the community, reference panel members and the decision-making authorities who will ultimately be receiving the recommendations. Having a clear desired outcome is also important when formulating the question or 'charge' to be considered.

The 2009 Citizens' Parliament was convened to:

- generate recommendations for reform of the Australian system of governance;

- provide a model and inspiration for deliberative civic engagement as a path toward better communities and governance;

- learn more about how citizens deliberate and the impacts of deliberation.

Because of the presence of different researchers, there were other less formal goals that the team hoped to achieve, including:

- showing Australian state and federal governments (both politicians and public servants) that a large-scale deliberative process can be organised to inform policy, legislative and constitutional development;

- demonstrating that many 'ordinary' citizens care about our political system and have good ideas about how to improve it;

- showing that citizens have the ability to understand and deliberate on complex issues;

- determining the impact of combining online and face-to-face deliberation; and

- providing an opportunity for academic study of a large-scale deliberative process.

Each component of the 2009 Citizens' Parliament (the regional meetings, the online deliberation platform, the parliament sitting and the overall process) had clearly defined goals. For more information about the goals please see:

Appendix 2. 2009 Citizens' Parliament goals. 


\subsection{GAINING COMMITMENT}

Gaining commitment and support from the main decision-making authority is important to the success of a deliberative democracy process such as a citizens' parliament. In an ideal deliberative democracy, the government initiates the process with a binding commitment to implement the participants' recommendations.

Ideally the ultimate decision makers - be they government, a government agency or authority, or a community group - should be involved from early in the planning process. Their commitment to the process and a clear statement about how they will take the findings into account, is important in planning a successful event.

Case studies have shown that participants devote themselves more diligently to their task when they are confident that their recommendations will be taken up. They also return to their communities with renewed civic pride and energy to promote their recommendations and engage in activity that benefits the community.
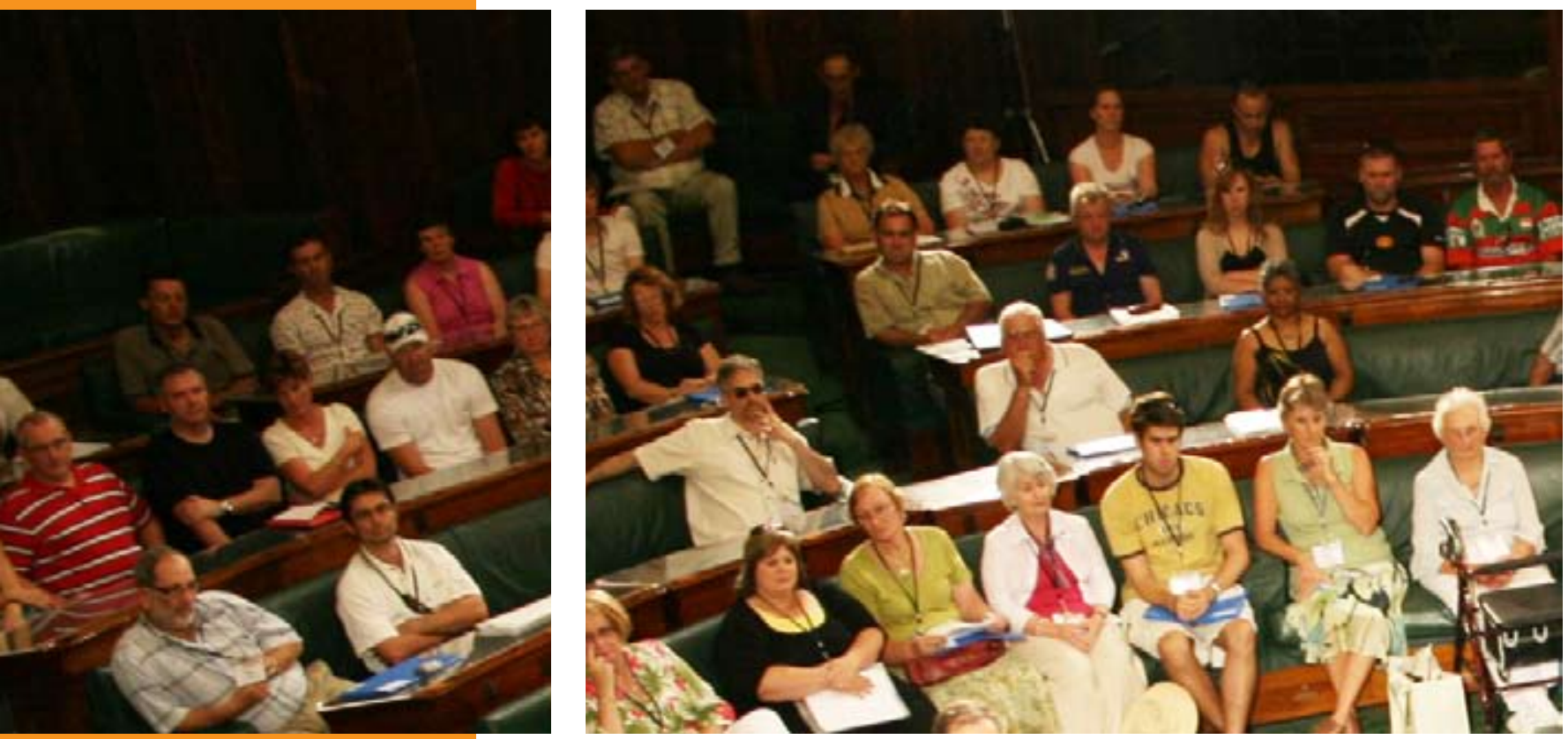

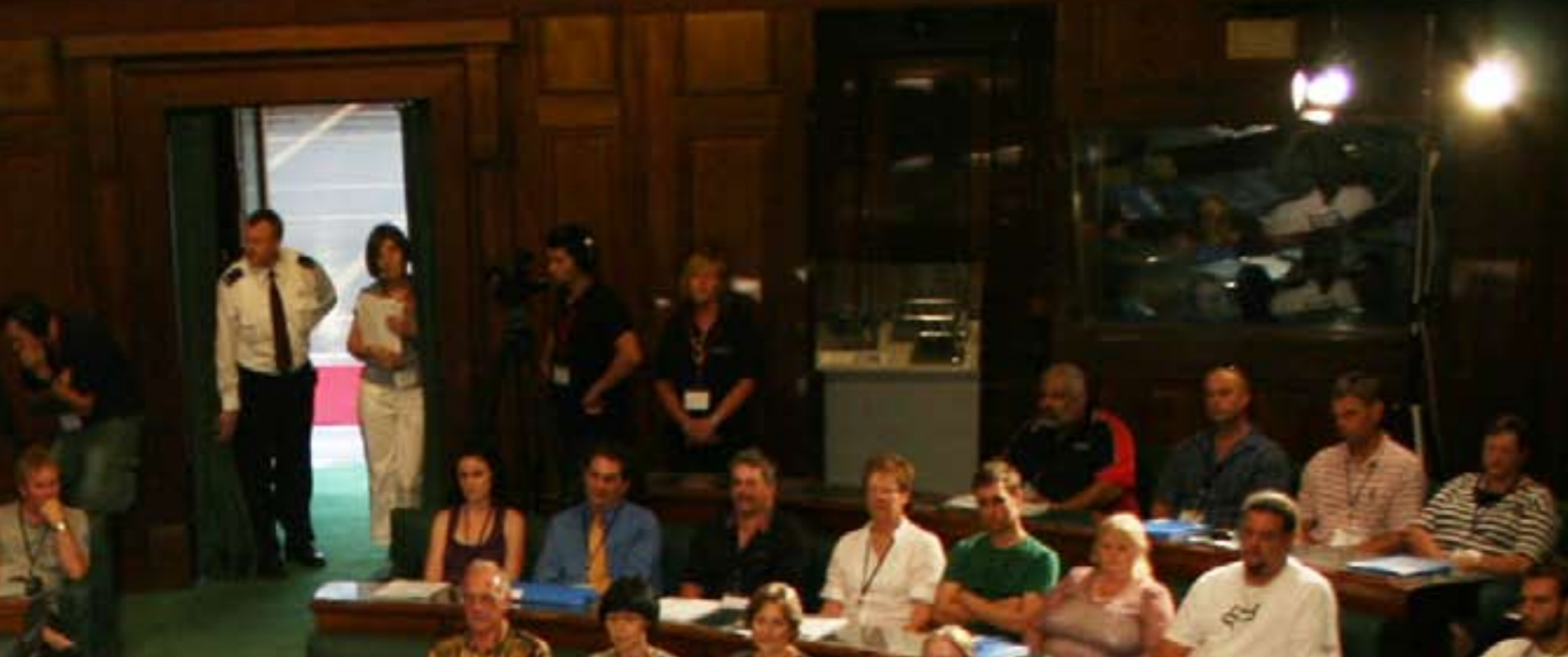

$I^{2}-2 x+2 \cdot x^{2}$

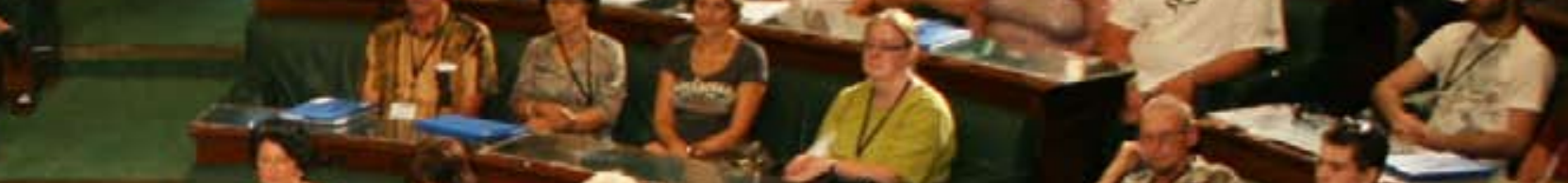

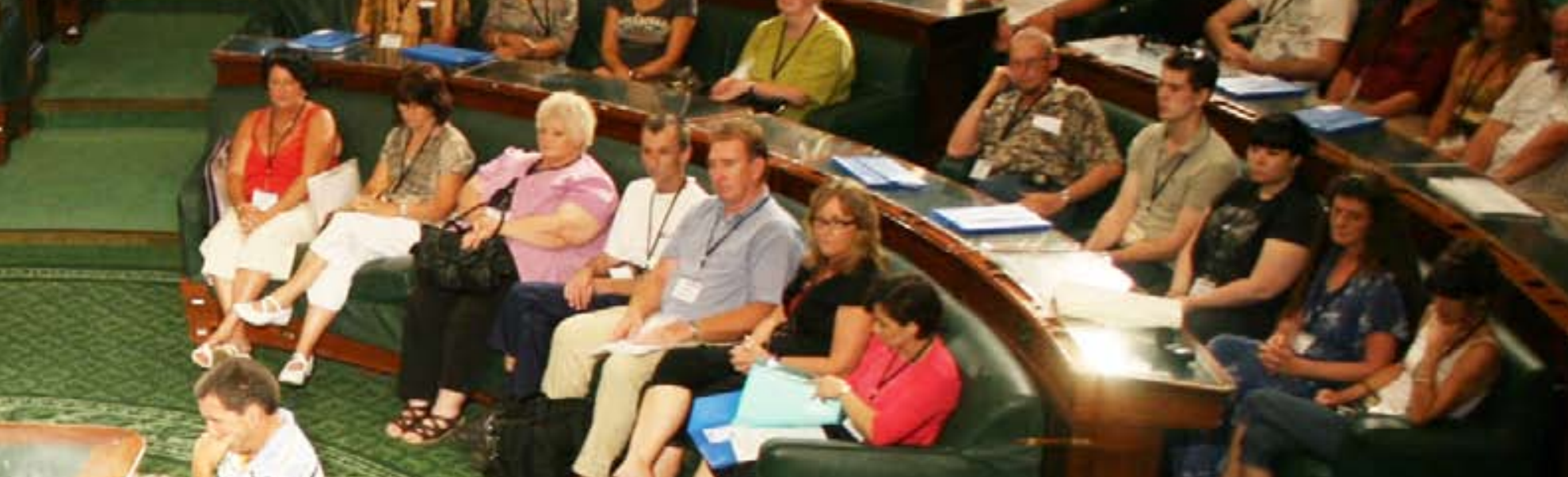

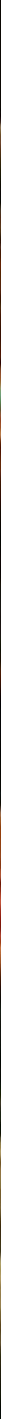




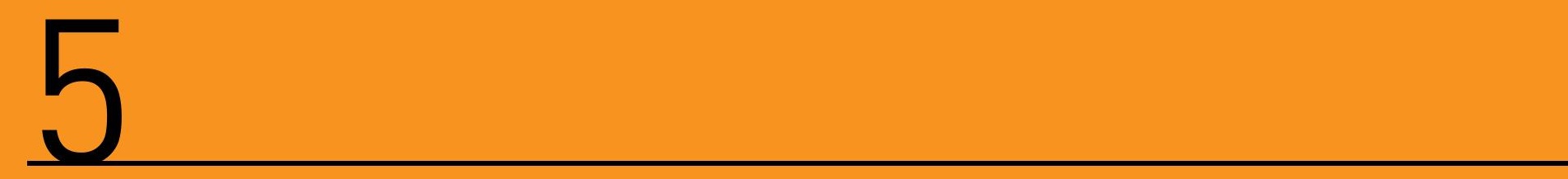

WHO IS INVOLVED IN A CITIZENS' PARLIAMENT?

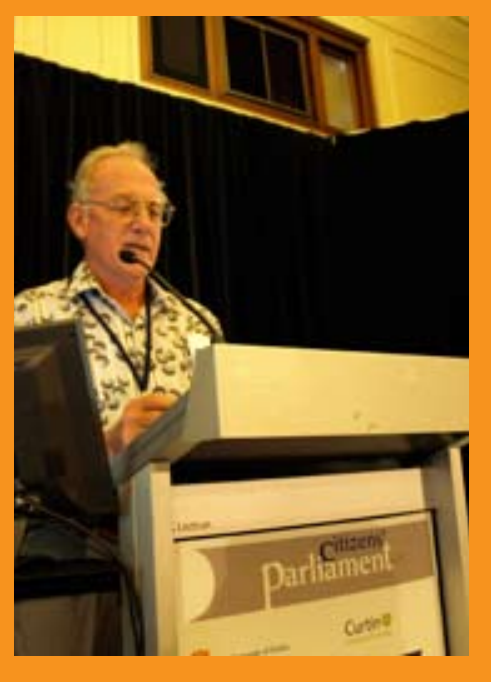

"People can

now feel they

have a say and are not just little

fish. This is about listening to the indians and not only, the chiefs."

Rosemary Chilcott, Citizen Parliamentarian. 


\section{WHO IS INVOLVED IN A CITIZENS' PARLIAMENT?}

A citizens' parliament is a major event. Australia's 2009 Citizens' Parliament involved not only 150 randomly selected citizens but also a team of around 200 support people including facilitators, researchers, volunteers, the reference panel and technical support staff.

\subsection{THE KEY ROLES}

\section{ORGANISERS/CONVENORS}

Deliberative democracy projects can be convened by various organisations, including governments themselves, as long as they are genuinely able to act neutrally in relation to the issue being considered. Due to the size of a citizens' parliament it requires a large organising team. The Australian 2009 Citizens' Parliament was organised by a series of coordinators who managed different project aspects including logistics, information technology, random selection, media liaison, the online parliament, facilitation and other aspects.

\section{REGISTERED PARTICIPANTS}

Of the 9000 invitations sent to citizens randomly selected from the electoral roll, just over 8000 were successfully delivered. From these, 2763 recipients registered their interest in being involved. All of the registered participants were invited to join the online deliberation platform, accessed via the 2009 Citizens' Parliament website, to develop preliminary proposals.

\section{CITIZEN PARLIAMENTARIANS}

From the 2763 citizens who registered, 150 were selected using stratified random sampling. These 150 citizen parliamentarians formed the heart of the 2009 Citizens' Parliament. Their role was to participate in deliberation of the 'charge' or issue facing them and to formulate recommendations together.

\section{THE CHAIRS}

The role of the chairs was to ensure the integrity of the process and to act as 'elders', bringing gravitas and legitimacy to the proceedings. The 2009 Citizens' Parliament was co-chaired by the Hon Fred Chaney and Dr Lowitja O'Donoghue. These eminent Australians were the public face of the event. They signed the formal invitation to participate and had oversight of the event as a whole, through introducing sessions, keeping the process on time, acknowledging the work being done and ensuring an outcome was achieved $^{10}$.

\section{THE REFERENCE PANEL}

Reference panels include individuals who are knowledgeable about the issue or charge being deliberated and can provide guidance and information to participants in a non-biased manner. The reference panel for a 2009 Citizens' Parliament took the role of 'brains trust', or critical advisers to the participants. The panel comprised prominent Australians familiar with how the government works and happy to lend their support. It included academics, senior public servants, commentators, activists and politicians. Members of the panel answered questions; indicated advantages, disadvantages and unintended consequences of proposed reforms;

10 See http://www.leadr.com.au/podcasts/Podcast\%20-\%20Citizens\%20Parliament.htm for podcast interviews with both the chairs.

"The conversations during the 2009

Citizens' Parliament

have been about

complex subjects.

Our congratulations

go to the citizens of

Australia who have

so enthusiastically

considered the

enhancement of their

democracy and those

who have encouraged

and recorded

that enthusiasm

through their own

expertise, and

excellent facilitation,

organisation and

research skills.

This enthusiastic

engagement is

enormously important

- it is the engagement

of the Australian

people which is at the

heart of maintaining

and improving our

Australian democracy."

Dr Lowitja

O'Donoghue, Citizens'

Parliament

Co-chair.

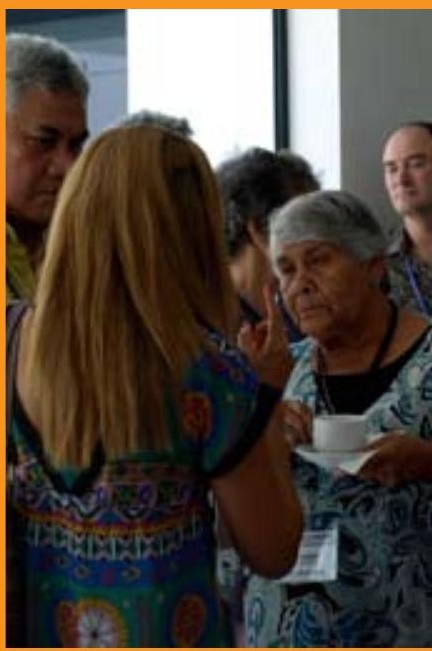


"It is at the tables where the real work

of deliberation

happens. The 2009

Citizens' Parliament

was blessed to have 23

very dedicated table

facilitators who used

their considerable

skill to assist the

parliamentarians

negotiate the tasks set

for them. More than

anyone, they made

the experience for

the citizens satisfying

through creating

an environment

conducive for

productive, respectful,

non-adversarial

discussions."

Dr Kath Fisher,

Coordinating

Facilitator. presented questions that participants should ask themselves about reforms; and helped participants alter some of their proposals. For membership of the reference panel see:

Appendix 3. Reference panel membership.

\section{OMBUDSMAN}

Dispute resolution experts Fiona Hollier and Phillip Hart provided an ombudsman service to the 2009 Citizens' Parliament. Their role was to use mediation or negotiation to help people resolve issues if they believed they had been treated unfairly by the 2009 Citizens' Parliament or its officers. This helped safeguard the community in its dealings with the 2009 Citizens' Parliament, and ensured that its processes were fair and accountable. The aim of the ombudsman was to resolve issues informally and quickly. The role was neutral, impartial and confidential within the limits of the law. The ombudsman could not give advice to either party, make decisions for a party, or impose a solution on the parties. The ombudsman service was not called upon during the 2009 Citizens' Parliament. For more detail about the role see:

Appendix 4. Ombudsman of the 2009 Citizens' Parliament.

\section{QUALIFIED FACILITATORS}

Experienced volunteer facilitators acted as allies of the citizen parliamentarians, ensuring that everyone had the opportunity to express themselves and encouraging a generous and empathetic response from listeners. Two lead facilitators orchestrated the proceedings from the front stage, clarifying the tasks to be undertaken at the table and amending the agenda when and if needed. The coordinating facilitator took responsibility for supporting the table facilitators during the deliberations as well as the debriefings.

Table facilitators asked open questions that required reflection and consideration, to help participants find deeper understanding of the topic at hand. They didn't express any favouritism and they invited participants to object if they perceived any bias, even if it was unintentional. Facilitators encouraged respectful and constructive dialogue, but didn't intervene unnecessarily. Importantly, facilitators of deliberative processes did not push participants to reach a consensus.

For more specific details about the roles of facilitators please see:

Appendix 5. Support team roles.

Appendix 6. Notes for facilitators.

\section{IT SUPPORT}

IT support staff managed the website and wrote the software for the random selection. During the event they oversaw the 21 st Century Dialogue technology, including the networking software and any IT problems at tables, as well as inputs to the PowerPoint presentations and reports. 


\section{RESEARCHERS}

Australia's 2009 Citizens' Parliament provided an opportunity for researchers of deliberative democracy to observe the changes in participants during deliberation and how the process works. This is not an essential role in a citizens' parliament, though it did play an important part of the 2009 Citizens' Parliament.

\subsection{SELECTING THE PARLIAMENTARIANS}

\section{RANDOM SELECTION}

A random selection of citizens captures the broad spectrum of lived experiences and political, social and ethical perspectives that inform decision-making that affects everyone.

The Australian 2009 Citizens' Parliament used random selection that generated a microcosm of the entire Australian population. It balanced the apparently contradictory mission of randomness and demographic matching by applying a variant of a technique called stratified random sampling.

Convenors made a commitment to include one participant from each of the 150 federal electorates, in such a way that the distribution of gender, age and education categories reflected as closely as possible that of the entire adult population. The team began by randomly selecting from registrations that identified as Aboriginal and Torres Strait Islander. They then divided the others by remaining electorate and drew randomly from each in turn. As the random selection proceeded, each category filled up. When a category reached the top of its tolerated quota, the team discarded all remaining registrations from all electorates who were in the same category. To mitigate the problem of running out of candidates before participants were drawn from all electorates, the electorate with the leanest count was always drawn next.

For more specific details of the random selection method please see:

Appendix 7. How citizens were randomly selected.
"Our youngest

participant was 18

our oldest 90 . We

began by sending

out letters to around

9000 people randomly

selected asking if

they'd be interested

in participating if

they were selected.

Approximately $30 \%$

said they would be.

"This is an

astonishingly high

positive response

rate, especially given

the demands we

would make on their

time, and gives the

lie to everyone who

says ordinary people

aren't interested

in participating in

politics."

Professor John Dryzek, Convenor.

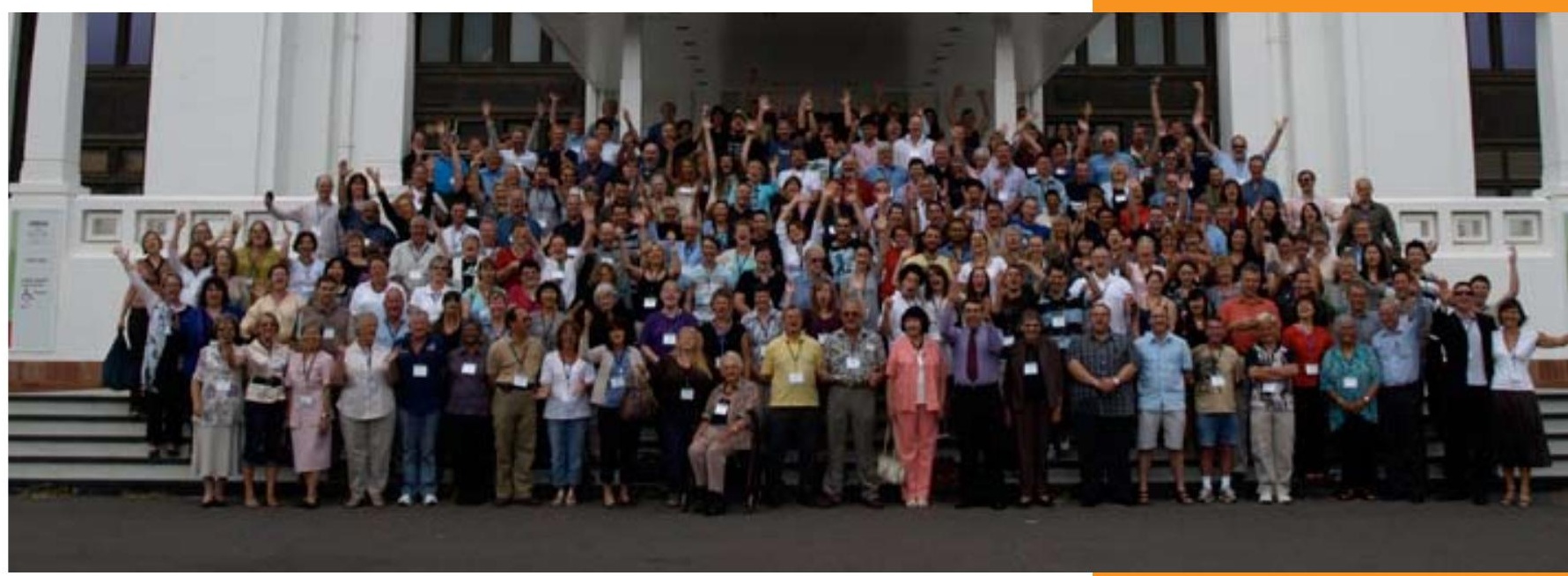




\section{COMMUNICATION}
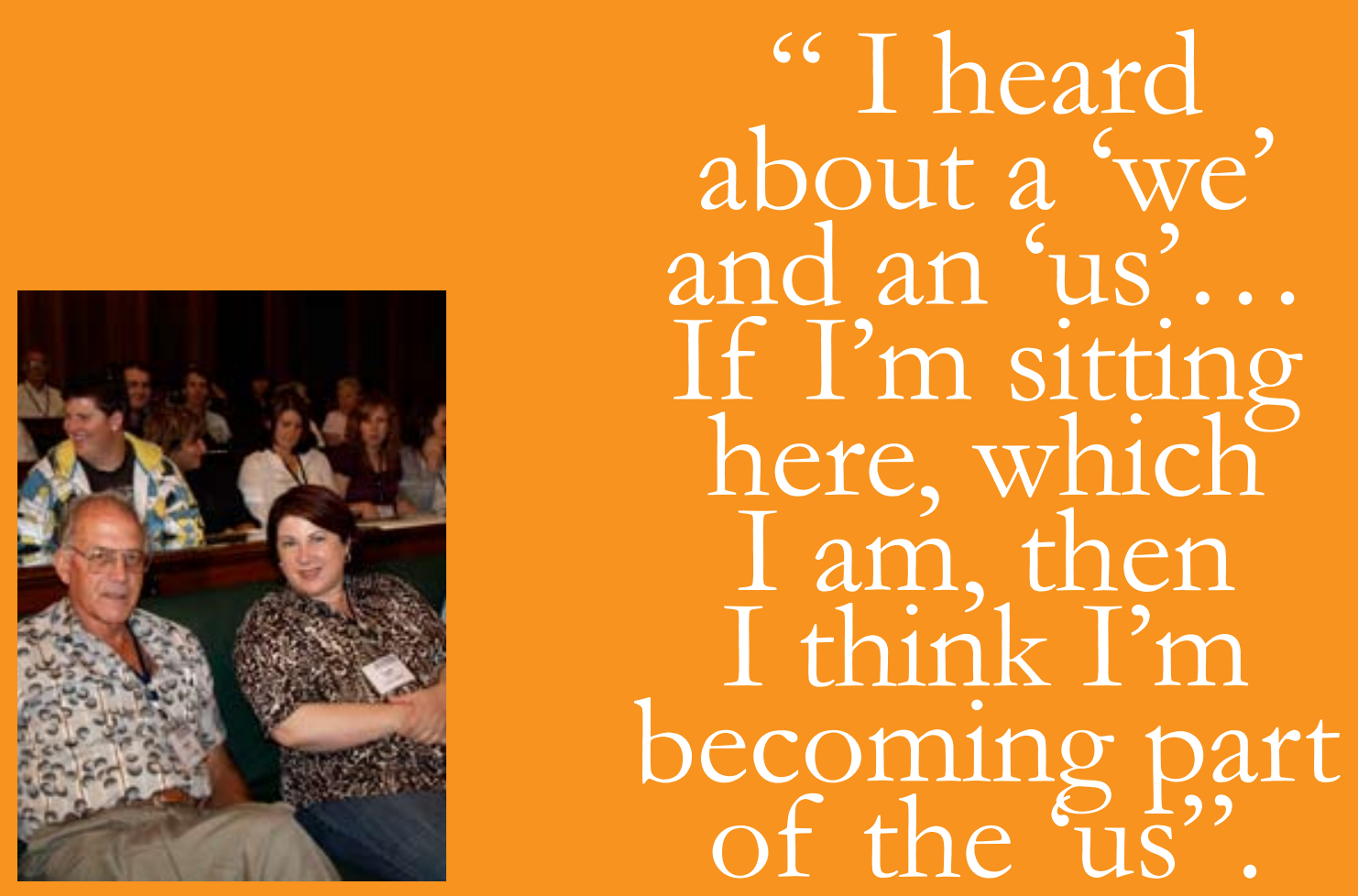

Victor Perry, Aboriginal Citizen Parliamentarian. 


\subsection{INVITATIONS}

Organisers knew it was vital that the initial invitations to participate in the 2009 Citizens' Parliament were credible and attractive. If they failed to interest recipients then the whole process could founder. Team members worked with experienced art directors and writers from the John Bevins advertising agency (pro bono) and Kathy Jones Associates to design and draft the invitations, trying and rejecting a number of ideas. Eventually they settled on a formal 'wedding invitation' style using good quality envelopes and beautifully embossed invitations.

The effort paid off. Out of approximately 8000 successfully delivered invitations, more than $30 \%$ resulted in a registration - an extremely high result for a direct mail campaign.

For a copy of the invitation please see:

Appendix 8. Invitation to participate.

Appendix 9. Letter to successful citizen parliamentarians.

\subsection{MEDIA STRATEGY}

Organisers developed a media strategy to increase public awareness of the 2009 Citizens' Parliament - an important component of the project. They aimed to maximise coverage by initially releasing stories about citizen parliamentarians to local and regional media outlets in their districts, thus providing a 'local' flavour to the stories. Coupled with some basic media training for participants, this approach drew positive responses from local media. The second part of the strategy was a focus on metropolitan media during the sitting of the 2009 Citizens' Parliament. While the metropolitan media showed interest a few days before, unfortunately the Victorian bushfires diverted media and public attention during the sitting.

The website www.citizensparliament.org.au contains media releases and a selection of the published stories. For an example of one regional media release please see:

\section{Appendix 10. Media Release: NSW-ACT citizens prepare for Australia's first Citizens' Parliament.}

\subsection{ELECTRONIC AND SOCIAL MEDIA}

The 2009 Citizens' Parliament website (www.citizensparliament.org.au) was a comprehensive resource for participants, media and the public, providing background reading, information on the convenors, links, podcasts, photos and articles. The site also included a publicly accessible threaded discussion forum, which was distinct from the private and secure online deliberation platform for registered participants.

Although social media was not a primary communication tool for the 2009 Citizens' Parliament, it was used as part of a broader communication strategy. The 2009 Citizens' Parliament sitting was live-blogged by Simon Sheik of the activist group Getup! The 2009 Citizens' Parliament had a Twitter identity (ozcp) and tweets, generated by the organisers, were displayed on the website. 


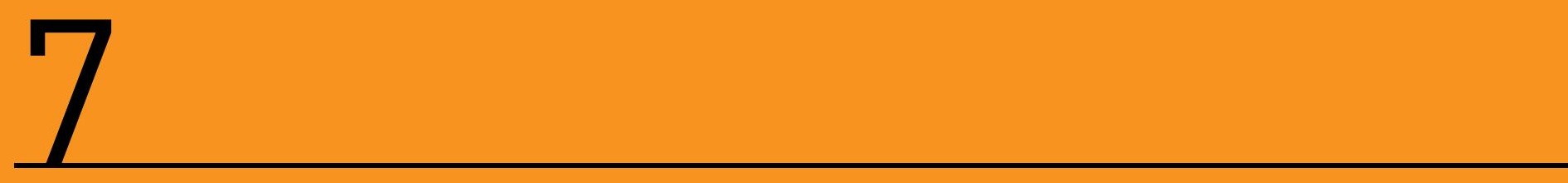

\section{HOW THE}

AUSTRALIAN CITIZENS'

PARLIAMENT WORKED

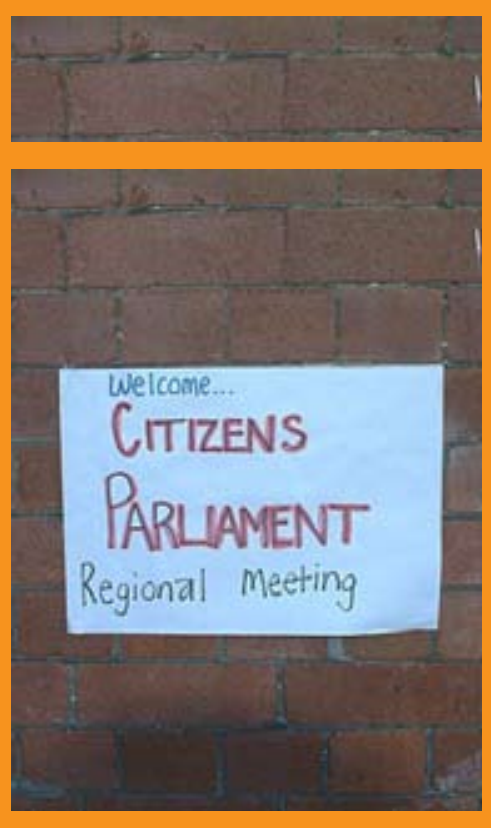

"... these citizen parliamentarians have come here from literally every electorate across the country." 


\subsection{SNAPSHOT: THE AUSTRALIAN CITIZENS' PARLIAMENT PROCESS}

The 150 randomly selected citizen parliamentarians of the 2009 Citizens' Parliament were given the task of answering the question:'How can Australia's political system be strengthened to serve us better?'

This question (or 'charge') was developed as a result of six 'World Café' events run by the newDemocracy Foundation in the lead up to the 2009 Citizens' Parliament to identify people's concerns about Australia's democratic system.

The citizen parliamentarians first participated in one-day regional meetings to get to know other participants in their area and to become familiar with deliberation and the task ahead. Many then continued their discussions through an online facility and finally they met at Old Parliament House, Canberra on 6-9 February 2009 to deliberate.

The deliberation process was based on the '21st Century Town Meeting' model which involves ingenious use of communications technology to synthesise the deliberations and the individual priorities of large numbers of participants.

This process generated a final list of proposals, of which the top six were presented by several of the citizens in the House chamber and were received by the Prime Minister's Parliamentary Secretary Anthony Byrne, representing the Prime Minister. They were also published in a final report ${ }^{11}$.

\subsection{DETAIL: WORLD CAFE EVENTS TO SET THE AGENDA}

NewDemocracy convened six World Cafés in Sydney and Melbourne during 2008 to help develop the agenda for the 2009 Citizens' Parliament. World Cafés are informal community forums where people think about the positions they hold in respect to the question, give reasons for the decisions they reach and listen to others respectfully ${ }^{12}$. These activities were designed to help set the agenda for the 2009 Citizens' Parliament. By allowing Australian citizens to speak freely about their political system, newDemocracy was able to understand the areas of concern.

The general format of the cafés featured 10 groups of five to eight people, who considered the main question and a list of sub-questions such as:

- What are the problems with the current political system? What are your concerns?

- What changes would you wish to see in order to better reflect community interests?

- What changes would you, as a group, wish to see?

The groups had 15 minutes for each of four rounds, with people in a completely different group for each round. They discussed each question while scribes recorded their findings. The stimulus question which made most sense to people survived as the charge for the 2009 Citizens' Parliament: How can Australia's political system be strengthened to serve us better?
BLOG :

Day 3 | A moment

to think about

those at home

Sunday

08 February 2009

$12: 22$

It's easy to

forget that

these citizen

parliamentarians

have come here

from literally

every electorate

across the

country.

That means

that many,

particularly

those from

Victoria, are

concerned about

their houses,

their property

and most

importantly their

family, friends

and neighbours

as a result of

the bushfires

spreading through

our parched

nation... It was

a reminder

that while we

can spend time

discussing the

long term and

sometimes the

abstract, there

are very real

and very personal

issues to attend

to right now.

This is no doubt

a dichotomy that

plays out equally

in the minds of

our politicians

and our citizen

parliamentarians.

Simon Sheikh,

GetUp!

11 The report can be downloaded from www.citizensparliament.org.au

12 For more information about this method see www.theworldcafe.com 
"There was an undeniable sense that these individuals, who had come together as people one night after work, had experienced

an activity that acknowledged their rights and capacities

as citizen. There was

a palpable sense

of empowerment

and worthwhile

dialogue. But most

importantly there was

strong commonality

regarding the issues

people identified

as predominantly

important."

Associate Professor Lyn Carson, Convenor.

\subsection{DETAIL: THE REGIONAL MEETINGS}

Citizen parliamentarians began their adventure at one-day meetings with others in their capital city or region. Around a dozen participants attended each meeting. The idea of the meetings was to introduce parliamentarians to each other and allow them to share knowledge, establish working relationships and try out deliberative techniques that would be used in the parliament sitting.

Using the World Café technique, citizen parliamentarians discussed questions relating to the charge, including

- What are the problems?

- What are your concerns?

- What actually needs to change?

- What ideas do you have to achieve change?

Facilitators helped participants with the process of converting ideas to proposals, including how to narrow down ideas and get more specific. For example, ideas could be categorised in four ways:

1. I can accept this idea and move on.

2. This idea interests me - I want to know more.

3. I'm not rejecting this idea but I'm wary.

4. I reject this idea.

The meetings helped participants plan how they would work together online to build proposals that could feed into the 2009 Citizens' Parliament sitting. Participants arranged to stay in contact with others in their area by phone or email.

For the agenda of the regional meetings please see:

Appendix 11. Regional meeting agenda.

\section{COMMENTS FROM REGIONAL MEETING PARTICIPANTS}

\footnotetext{
66 My participation [was] being taken seriously. There was no indication that my thoughts were trivial."

66 [I am still anxious about] the computer interaction. It has been a while since I used one. '?

66 [I found it difficult] writing in English, though I understood much, nearly all of what was spoken.'

66 I was very nervous at the beginning but one of the volunteers (Abbie) reassured me not to worry. She was a big help."

66 We got a good balance of info as well as sharing."

66 It was something completely different for me. I enjoyed listening and giving input into our discussions.'

66 Felt very much at home with the other members of the group. Varied activities made the day very interesting and enjoyable."

66 The butterflies settled. A-OK. Roll on Canberra.' '

66 [I still feel anxious about] whether, despite our best efforts and goodwill, there is the political will to entertain constructive change.'
} 


\subsection{DETAIL: THE ONLINE PARLIAMENT}

The second phase of the 2009 Citizens' Parliament process was the online parliament, which commenced after the regional meetings and ran until the 2009 Citizens' Parliament sitting. Its purpose was to generate an initial set of proposals which could be elaborated upon in Canberra. Initially it was to be open only to the 150 selected participants. But quite late in the planning the convenors decided that all the original 2763 people who registered would be invited to participate in the online parliament. The 150 Citizen Parliamentarians had no special status or identification in the online parliament.

The online parliament was a goal-driven online deliberation process to help the participants form teams and develop detailed proposals for change. CivicEvolution ${ }^{13}$ provided the online deliberation platform and support for the online parliament. The online parliament is illustrated further in the participant orientation video ${ }^{14}$.

The online parliamentarians developed proposals in teams formed around common interests and concerns. A proposal idea could be suggested by any of the registered participants. At least four registered participants had to sign up for a proposal idea before the team could begin deliberations. Deliberations were only open to team members and teams were limited to 25 or fewer members. These small groups helped ensure a respectful environment where team members could engage with each other productively.

Once a team formed around a proposal idea, the team members could start deliberating on a series of questions that would lead them to define the problem they wanted to address, brainstorm possible solutions, analyse the pros and cons of the possible solutions, and finally make a recommendation. While this generic format for producing a policy paper was an ambitious undertaking for citizen deliberations, it also provided gravity and a clear goal to their work as a team.

\section{DEVELOPING A PROPOSAL}

\section{STEP 1: DEFINE THE PROBLEM}

How can you explain this problem in 1-2 sentences?

Why is this a problem and what are the root causes?

Who is affected by this problem? Try to consider all of the stakeholders.

Why should citizens care about this problem?

\section{STEP TWO: EXPLORE POLICY OPTIONS}

Do you know of anything that has been done or proposed to address this problem thus far?

What are other potential courses of action to deal with this problem?

\section{STEP THREE: ADVANTAGES AND DISADVANTAGES OF EACH POLICY OPTION}

Can you state the advantages and disadvantages of this option that was described in the previous step? Think first about how well this option satisfies your values (e.g. justice, fairness, efficiency, whatever values you consider important). Start with this question: What values are appropriate to keep in mind when you compare the options?

13 CivicEvolution is free for use by citizens engaged in community problem solving and offers hosted services for a fee to agencies and organisations that want to provide productive engagement opportunities to their constituents. See www.civicevolution.org

14 View the participant orientation video at http://civicevolution.org/ce/aucp.html

"I start an online proposal about the importance of civics in education, encompassing issues like the workings of Australia's

political system;

the background

to Federation and

its implications on political structures and laws; the different roles of the houses of parliament; the separation of political and judicial powers; and citizens' rights.

Several people join up; we start a sporadic discussion... My online group fails to get our proposal through all the necessary hoops for it to be formally considered by the citizens' parliament."

Pete Cruttenden, Citizen Parliamentarian. 
Day 1 Contrast

Friday

06 February 2009

$15: 50$

It's said that politics is a sport for old

white men in suits, and never was that more

true than in the bowels of Parliament House in Canberra today...

Ah, it's great to see true democracy in action... but of course to see that you'll have to walk (if you're game to leave air-con) across the parched lawns to old Parliament House. There you'll find 150 citizens, selected at random to represent the Australian populace, deliberating on how to 'improve the

Australian political and democratic system'. The 'Citizens

Parliament' will meet for four days to discuss ideas like keeping the bastards accountable to election promises, reforming voting and allowing

the public to initiate referenda (republic here we come!)

The participants have just heard from Senator

Faulkner (at somewhat soporific length) about the Government's agenda, but what we're really interested in is the ideas this process can generate. After all, is it possible for 150 people to agree on anything? I'll keep you posted on that one.

on appearances at

least, this is a much more interesting

Parliament than the one across the lawn. The

participants, dressed in everything from Rabbitoh's jerseys to silk kimonos, are certainly more colourful than the suited old men on the hill.

from 'Citizens Parliament' old Parliament House Sam - your resident liveblogger.
With those values at the back of your mind, what are the advantages and disadvantages of this policy option?

\section{STEP FOUR: YOUR RECCOMENDATION}

Do you want to recommend that this option goes forward to be considered by others-why?

The CivicEvolution process helped teams succeed by breaking down the complexity of developing a policy paper into a series of concrete questions, which the teams deliberated and answered. It then streamlined the process of collaboratively developing answers by making it easy for team members to suggest, rate and edit answers. By focusing on deliberating and answering questions, the teams were able to develop their proposals. CivicEvolution also provided daily email reports, email notification of comment replies and calls to action to help teams advance through the self-managed proposal process. The clear goals and process allowed teams to focus on their ideas instead of worrying about formats, processes, and tools.

Deliberation took place in a team workspace dedicated to each question. The question provided context and direction to help the team keep itself focused. In addition to commenting on the question and replying to others' comments, team members were encouraged to suggest answers to the question at hand. The suggested answers stood out from the threaded discussion to ensure their visibility. All team members were further encouraged to discuss, rate, and even edit the suggested answers. An edit history provided transparency to ensure members edited in good faith. The answers captured the wisdom, knowledge and values of the team as they discussed each question. The answers that were developed in each question workspace and rated favourably by the team flowed through to the team's proposal document.

Comments and answers in the team workspace were limited in length to encourage clear and concise statements and provide opportunities for people to engage in dialogue as opposed to lobbing monologues at each other. Over 1300 comments and 800 answers were made by online parliamentarians. There was not a single incidence of 'flaming' or abuse.

Fifty-eight ideas were proposed and 25 teams started deliberating proposals relevant to the 2009 Citizens' Parliament charge of improving Australia's system of government. Eleven proposals were completed and endorsed by their teams. These 11 proposals became the starting point for the assembly in Canberra.

For more details on the online parliament see:

Appendix 12. Online parliament home page.

Appendix 13. Screenshot of online proposal development.

Appendix 14. Summary of the 11 proposals which came out of the online parliament.

Appendix 15. One full proposal showing problem recommendation and justification. 


\subsection{DETAIL: THE 2009 CITIZENS' PARLIAMENT SITTING}

The 150 citizen parliamentarians arrived at Old Parliament House in Canberra in early February 2009 to begin their face-to-face deliberation. They were housed in student accommodation at the University of Canberra and were immediately faced with challenges including a heat wave, no air conditioning in the accommodation and the unfolding of the bushfires in Victoria. However they courageously maintained their focus.

Care was taken to ensure that the four-day event allowed participants to achieve their goals. The aims of the sitting were to:

- Provide the space and opportunity for dialogue and deliberation on 'How can Australia's political system be strengthened to serve us better?'

- Enable participants to explore different ways to achieve this through deliberative processes that facilitated participant understanding of different views, learning new ideas, testing assumptions, identifying values, weighing options and developing priorities.

- Provide the opportunity for participants to develop a final report of their recommendations, and to have that report heard and seriously considered by those in positions of influence.

Organisers drew up a plan for the four days, with a key focus for each day:

- Day 1 Aim - Understanding what we want to achieve together at the 2009 Citizens' Parliament.

- Day 2 Aim - Broadening our perspectives.

- Day 3 Aim - Determining what is most important to us.

- Day 4 Aim - Consolidating and delivering our recommendations.

Discussion ground rules were set at the start and applied to everyone citizen parliamentarians, organisers and support staff alike. They were:

- Speak openly and honestly.

- Listen carefully to what others have to say.

- Treat everyone with respect.

- Keep comments brief and to the point of the question/work sheet.

- Stay on task.

- If you need to take a break - do so.

The four-day agenda included dialogue, reflections, presentations, panel discussions, and a World Café process. To see the details of the daily agenda please go to:

Appendix 16. Citizens' parliament mini-agenda.

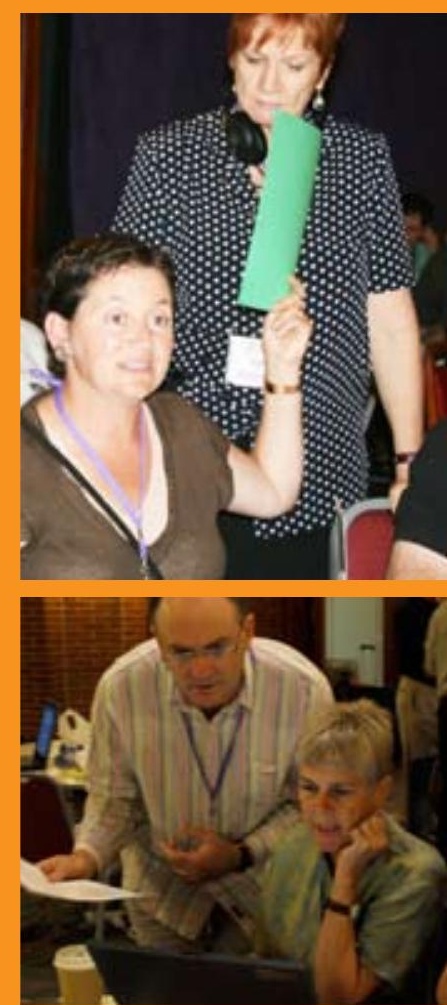




\begin{tabular}{|c|c|c|}
\hline BLOG: & \multirow{3}{*}{\multicolumn{2}{|c|}{ 7.6 DAY ONE: UNDERSTANDING WHAT WE WANT TO ACHIEVE }} \\
\hline \multirow{2}{*}{$\begin{array}{c}\text { Day } 2 \text { | Behind } \\
\text { the curtain }\end{array}$} & & \\
\hline & & \\
\hline \multirow{3}{*}{$\begin{array}{r}\text { Saturday } \\
07 \text { February } 2009 \\
16: \odot 2\end{array}$} & & AGENDA DAY ONE \\
\hline & $14: 30$ & Welcome \\
\hline & $14: 50$ & Official address \\
\hline \multirow{3}{*}{$\begin{array}{r}\text { Democracy doesn't } \\
\text { just happen, } \\
\text { and the machine } \\
\text { behind Citizens } \\
\text { Parliament is }\end{array}$} & 15:10 & $\begin{array}{l}\text { Overview of what we have done already; what we want to } \\
\text { achieve and how }\end{array}$ \\
\hline & $15: 20$ & Short presentations outlining the prioritised online proposals \\
\hline & $15: 50$ & AFTERNOON TEA \\
\hline \multirow{2}{*}{$\begin{array}{r}\text { well oiled. There } \\
\text { are, on my rough } \\
\text { count, } 20 \text { admin } \\
\text { volunteers, } \\
15 \text { volunteer }\end{array}$} & $16: 20$ & $\begin{array}{l}\text { Small group introductions and dialogue - what we want to } \\
\text { achieve together }\end{array}$ \\
\hline & $16: 50$ & $\begin{array}{l}\text { Individual/group input to computers; changes to online } \\
\text { proposals }\end{array}$ \\
\hline \multirow{3}{*}{$\begin{array}{r}\text { facilitators, } \\
3 \text { computer } \\
\text { technicians } \\
\text { and } 6 \text { caterers } \\
\text { backstage here } \\
\text { at citizens' }\end{array}$} & $17: 40$ & $\begin{array}{l}\text { Small group dialogue - how this deliberation could be } \\
\text { different }\end{array}$ \\
\hline & 18:10 & Closing remarks \\
\hline & 18:15 & Close and distribution of day one preliminary report \\
\hline
\end{tabular}

The 2009 Citizens' Parliament began on Friday February 6 in the chamber of the House of Representatives with a welcome by Cabinet Secretary and Special Minister of State, Senator John Faulkner. Senator Faulkner talked about the Federal Government's commitment to community consultation and the core principles of openness, debate and deliberation. He noted that policy should not be limited by the usual voices who we hear from all the time. Senator Faulkner indicated that the government would look closely at the outcomes of the 2009 Citizens' Parliament.

The top five proposals prioritised by online parliamentarians were presented by their team representatives to the opening session of the 2009 Citizens' Parliament sitting. After the opening ceremony, the participants began the work of deliberating about how to strengthen our democratic system. The 11 proposals developed from the online parliament were tabled and discussed and a new expanded list of proposals developed.

Participants mostly worked in small tables of six or seven with a facilitator to ensure that all had an opportunity to express their opinions and hear the opinions of others, including visiting experts. During the deliberation, citizens' parliamentarians were divided into 23 tables in the Members' Dining Room of Old Parliament House, each with a volunteer facilitator. Participants would periodically move between tables. They deliberated particular proposals, and could introduce new proposals or synthesise existing ones.

Using the 21st Century Dialogue approach, which involved the combination of small group facilitated deliberation and networked computer technology, each table's key themes could be broadcast to the entire room. At each table, ideas were submitted to the computer including individual, team and strongly held minority views. Table inputs were relayed to a theme team who synthesised the results and displayed them to the room on large screens.

Preferential rankings were projected back into the room. At the conclusion of each day, participants were given a preliminary report of the outcomes of the day's deliberations. 


\begin{tabular}{cl} 
08:30 & AGENDA DAY TWO \\
\hline $08: 40$ & $\begin{array}{l}\text { World Café: } \\
\text { a) When our democracy is at its best, what is it we appreciate? } \\
\text { b) How can it be more like this more often? } \\
\text { C) What can be learnt from this? }\end{array}$ \\
\hline 09:40 & $\begin{array}{l}\text { First panel discussion - commentary on proposals - pros, } \\
\text { cons, gaps, issues of interest }\end{array}$ \\
\hline 10:10 & Developing questions for panel \\
\hline $10: 30$ & MORNING TEA \\
\hline $11: 00$ & First panel responses to key themes/questions \\
\hline $11: 35$ & Second panel discussion - additional options to consider \\
\hline $12: 05$ & Developing questions for second panel \\
\hline 12.50 & LUNCH \\
\hline $13: 15$ & $\begin{array}{l}\text { Second panel responds to key themes/questions and } \\
\text { additional creative options }\end{array}$ \\
\hline $14: 25$ & $\begin{array}{l}\text { Reflective conversation - overall reflection on proposals thus } \\
\text { far }\end{array}$ \\
\hline $14: 50$ & $\begin{array}{l}\text { Selecting options - the issues/ideas we want to develop } \\
\text { further }\end{array}$ \\
\hline $15: 30$ & AFTERNOON TEA \\
\hline $16: 00$ & Selecting options (continued) \\
\hline
\end{tabular}
day of debate and discussion. I'm filled with intrigue, as this is my first day of observing the process. As a deliberative democracy fan I await with baited breath the outcomes of the day in the hope that today's session will deliver outcomes people are proud of.

One big question on many people's minds today is the fundamental role of Government and the responsibilities of different levels of Government.

Citizen

Parliamentarians raised a number of issues in this morning' question and answer session from the appropriateness of a Bill of Rights to the overregulation of Government.

In discussing these issues there is an enormous sense of collaborative spirit and a feeling of pride amongst many who are genuinely excited about being a part of this process.

As one

Parliamentarian put it (and I'm paraphrasing: "I'm very proud to be here. You could raise the point that this is like a comma. Here today and gone tomorrow... I'd like something to show my grandchildren that I was here".

More to come!

Simon Sheikh, GetUp! 
Day 3 | Deep in debate... Sunday

08 February 2009 $14: 32$

Citizens

Parliamentarians are busily engaging in a process of deliberative democracy. Some 47 proposals are being discussed with the aim of whittling these down. I'll be looking under the bonnet of some of the most hotly contested ideas in my next few posts.

\section{A Bill of Rights} Citizen

Parliamentarians are considering what rights should be listed in a Bill of Rights and whether or not one is needed at all. As an example

Parliamentarians are looking at rights including life, liberty and property rights and rights to freedom of thought, belief, speech \& assembly.

Parliamentarians are separated

into small groups to discuss the

prioritisation of these issues.

while some are quite calm as they attempt to use a consensus model of decision making, others are finding the process difficult.

I'll let you know how things progress..

Simon Sheikh, GetUp!

\begin{tabular}{|c|c|}
\hline & AGENDA DAY THREE CONT'D \\
\hline $11: 40$ & $\begin{array}{l}\text { Prioritisation - selecting the top } 10 \text { from our combined list of } \\
\text { proposals }\end{array}$ \\
\hline $11: 55$ & $\begin{array}{l}\text { Prioritisation - which characteristics are most important to a } \\
\text { healthy political system? }\end{array}$ \\
\hline $12: 10$ & $\begin{array}{l}\text { Fishbowl - which of our proposals come to mind as best } \\
\text { reflecting our \#1 characteristic? }\end{array}$ \\
\hline $12: 35$ & $\begin{array}{l}\text { Prioritisation - which proposals best reflect our \#1 } \\
\text { characteristic of a healthy democracy }\end{array}$ \\
\hline 12:55 & LUNCH \\
\hline $13: 40$ & $\begin{array}{l}\text { Small group dialogue - which proposals come to mind as best } \\
\text { reflecting \#2 characteristic? }\end{array}$ \\
\hline $14: 00$ & $\begin{array}{l}\text { Prioritisation - proposals most reflecting our \#2 characteristic } \\
\text { of a healthy democracy }\end{array}$ \\
\hline $14: 10$ & $\begin{array}{l}\text { Small group dialogue - which proposals come to mind as } \\
\text { being our most innovative? }\end{array}$ \\
\hline $14: 30$ & Prioritisation - our most innovative proposals \\
\hline $14: 45$ & $\begin{array}{l}\text { Small group dialogue - which proposals would be the easiest } \\
\text { to implement }\end{array}$ \\
\hline 15:05 & Prioritisation - our easiest to implement initiatives \\
\hline $15: 20$ & AFTERNOON TEA \\
\hline 15:50 & $\begin{array}{l}\text { Small group dialogue - which proposals would be the most } \\
\text { important in the long term? }\end{array}$ \\
\hline $16: 10$ & Prioritisation - our most important proposals in the long term \\
\hline $16: 25$ & Quiet reflection / time-out \\
\hline $16: 45$ & $\begin{array}{l}\text { Discussion of model of final report recommendations, } \\
\text { suggestions and changes }\end{array}$ \\
\hline $17: 20$ & $\begin{array}{l}\text { Eliciting citizens' parliament volunteers to present the final } \\
\text { report recommendations }\end{array}$ \\
\hline $17: 25$ & Closing remarks \\
\hline $17: 30$ & Close and distribution of day three preliminary report \\
\hline
\end{tabular}

By day three, 51 proposals had been created. Before prioritising this lengthy list, participants considered what the essential characteristics of a healthy democracy were. These characteristics became the criteria they employed in prioritising the proposals. They were:

- freedom

- transparency

- guaranteed education for all

- justice and fairness in government

- inclusiveness

- access for all to the political system

- access to information

- diverse media

- active citizenship. 
The list was further reduced to determine the top five characteristics that would lead to the sort of democracy they would wish to leave for future generations. The top five fundamental characteristics of a healthy political system, ranked by priority, were:

1. Freedom

2. Transparency

3. Guaranteed education for all

4. Justice and fairness in government

5. Inclusiveness.

Participants prioritised proposals by applying a budget allocation technique: "If you had $\$ 100$ to spend, on which reforms would you put your money?"The priorities were then tabulated using the networked computers. By using this process, the participants reduced the 51 proposals to a more manageable list of 13.

\section{THE TOP 13 PROPOSAL IDEAS ACCORDING TO OVERALL VALUES}

The 13 proposal ideas considered most likely to deliver the political system the citizen parliamentarians would like to leave to the next generation were:

1. Reduce duplication between levels of government by harmonising laws across state boundaries.

2. Empowering citizens to participate in politics through education.

3. Accountability regarding political promises and a procedure for redress.

4. Empowering citizens to participate in politics through community engagement.

5. Change the electoral system - optional preferential voting.

6. Youth engagement in politics.

7. Recognise Aboriginal and Torres Strait Island peoples in the constitution.

8. Bill of rights and responsibilities.

9. Extend and fix the term of government.

10. Open and accessible government.

11. Remove or reduce state level of government.

12. Resurrect the republic debate and/or a referendum.

13. Citizen initiated referendum.

Interestingly, and perhaps unsurprisingly, the 13 proposed ideas were closely aligned to the original 11 proposals that were developed online prior to the 2009 Citizens' Parliament sitting.

The next step involved applying the most important values of freedom and transparency to each of the 13 proposals. One by one, each proposal was considered to determine if it best met the characteristic of freedom and transparency. Participants also analysed what proposals were the most innovative, easiest to implement and most important in the long term.
BLOG :

Day 3 | Some

more interesting

questions raised

Sunday

๑8 February 2009

12: 05

We've just

stepped out of

a question and

answer session.

Questions about

whether or not

individuals can

be co-opted to

sit in Parliament

were raised

and discussion

had about the

coopting of

individuals into

Cabinet for

example.

What's amazing

me is that the

majority of

conversation

and questions

raised this

morning concern

democratic

process and not

policy issues.

These

parliamentarians

have shown their

willingness to

discuss these

complex process

points.

I'm also left

quite surprised

by the level of

participation...

These randomly

selected Citizen

Parliamentarians

are rising to the

challenge.

Simon Sheikh, GetUp! 
Day 4 begins Monday

๑9 February 2009

$11: 17$

The back of house operation that supports this is something to be seen! There are more 21 inch monitors than I've ever seen in one place and laptops are everywhere.

Technology and politics go hand in hand and the question on many people's minds is where to from here? How can we use technology to keep communicating once the event is over?

I'll report developments as they happen today

- so stay tuned! Simon Sheikh, GetUp!

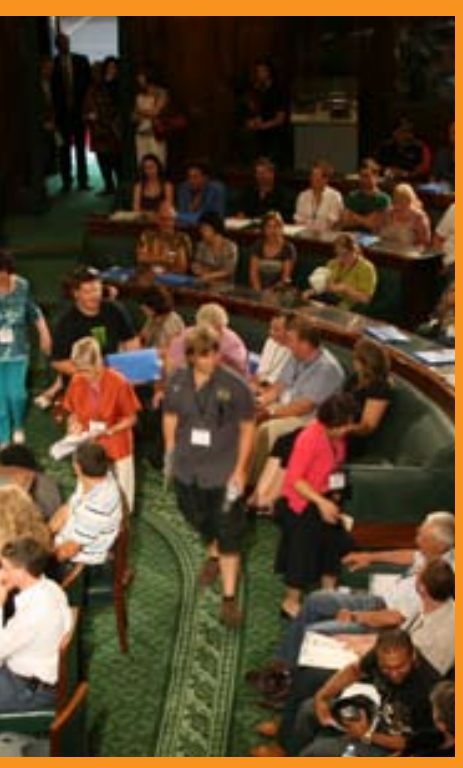

When all the prioritisation activities were considered in total, the following six proposals surfaced as those with most support:

1. Reduce duplication between levels of government by harmonising laws across state boundaries.

2. Empower citizens to participate in politics through education.

3. Accountability regarding political promises and procedure for redress.

4. Empower citizens to participate in politics through community engagement.

5. Change the electoral system to optional preferential voting.

6. Youth engagement in politics.

\subsection{DAY FOUR: CONSOLIDATING AND DELIVERING OUR RECOMMENDATIONS}

\begin{tabular}{|c|c|}
\hline & AGENDA DAY FOUR \\
\hline 08:30 & Welcome, recap of day three and overview of day four \\
\hline 08:40 & $\begin{array}{l}\text { Distribution of draft final recommendations report -read/ } \\
\text { clarify/amend? }\end{array}$ \\
\hline 08:55 & Small group dialogue - highlights, lowlights, insights \\
\hline 09:30 & $\begin{array}{l}\text { Distribution of final report recommendations - explanation of } \\
\text { any changes }\end{array}$ \\
\hline 09:35 & $\begin{array}{l}\text { Citizens' parliament volunteer representatives practice } \\
\text { presentation of final report recommendations }\end{array}$ \\
\hline 10:05 & MORNING TEA \\
\hline 10:40 & Welcome to guests - MPs and media \\
\hline 10:45 & $\begin{array}{l}\text { Presentation of final report to government representatives } \\
\text { and media }\end{array}$ \\
\hline 11:05 & Opportunity for government to respond \\
\hline $11: 25$ & $\begin{array}{l}\text { Thank you to guests and citizens' parliamentarians, and } \\
\text { depart the Assembly Chambers }\end{array}$ \\
\hline 11:40 & $\begin{array}{l}\text { Small groups - next steps: how we can move forward, } \\
\text { keeping'we, the people' at the forefront }\end{array}$ \\
\hline 12:10 & $\begin{array}{l}\text { Debrief - expectations versus reality; possible impacts; } \\
\text { learnings about self, others, democracy }\end{array}$ \\
\hline 12:45 & LUNCH and opinion charting \\
\hline 14:00 & Final survey \\
\hline 14:10 & $\begin{array}{l}\text { Citizens' parliament response - cameo experiences of the } \\
2009 \text { Citizens' Parliament - e.g. through skit, poem, essay, } \\
\text { song }\end{array}$ \\
\hline $14: 20$ & Short video of experiences of the 2009 Citizens' Parliament \\
\hline 14:35 & Finals words and thank you \\
\hline $14: 45$ & Close and distribution of day four report \\
\hline
\end{tabular}


On day four, the citizen parliamentarians considered their final recommendations and report and reflected on their experiences. A group was selected to present their recommendations to the government.

The top ideas were:

1. Reduce duplication between levels of government by harmonising laws across state boundaries.

2. Empower citizens to participate in politics through education.

3. Accountability regarding political promises and a procedure for redress.

4. Empowering citizens to participate in politics through community engagement.

5. Change the electoral system to optional preferential voting.

6. Youth engagement in politics.

7. Recognise Aboriginal and Torres Strait Island peoples in the constitution.

8. Bill of rights and responsibilities.

9. Extend and fix the term of government.

10. Open and accessible government.

11. Remove or reduce state level of government.

12. Resurrect the republic debate and/or a referendum.

13. Citizen-initiated referendum.

The recommendations were presented by several of the citizen parliamentarians in the House Chamber, and were received by the Prime Minister's Parliamentary Secretary Anthony Byrne, representing the Prime Minister. 


\section{OUTCOMES}

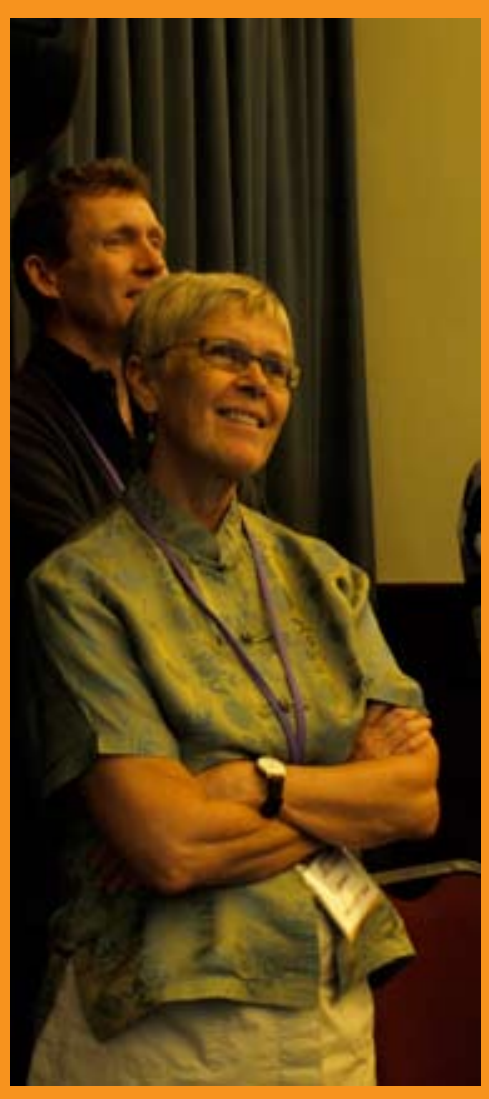

"There was a palpable sense of empowerment and worthwhile dialogue. But most importantly there was strong commonality regarding the issues people identified as predominantly important. 


\subsection{FINDINGS OF THE RESEARCH}

The researcher team studied many aspects of the 2009 Citizens' Parliament including the quality of the conversations, the legitimacy of the deliberative approach, the experiences of participants and shifts in attitudes and opinions over the course of the event. At the time of writing this handbook, findings have not yet been published.

This was the first large-scale deliberative democracy event where all conversations at tables, amongst the theme team and at the facilitator briefings, were audio-recorded and transcribed. The detailed content of the deliberations was captured by the networked computers used to communicate ideas to the theme team and render them on the big screen and in the daily reports. Researchers took notes about what they witnessed and their immediate thoughts about it and the participants responded to several questionnaires throughout the parliament.

Researchers from ANU applied both 'Q-sort' methodology and a preference ranking survey to track changes in participants' views through the process. A Q-sort is a model of the individual's orientation to an issue area - in this case, Australian democracy. It is constructed from a citizens' ranking of 48 statements about democracy in Australia. The citizen participants were asked to complete the Q-sort four times: when they were first recruited to be part of the Citizens' Parliament (this was done online), at the regional meetings, when they arrived in Canberra for the main meeting, and at the conclusion of the Canberra meeting.

All these Q-sorts could be analysed statistically to reveal the basic underlying patterns of discourse among the participants. The researchers found four basic positions or factors as follows:

- A: Inclusion (the political system needs to be made more inclusive, especially when it comes to various minority groups).

- B: Disaffection (cynicism about and alienation from the system).

- C: Contentment (approval of the way the system works and the citizen's place within it).

- D: Empowerment (stressing the need for more effective citizen participation in politics).

The way that individuals changed their dispositions over the course of their participation could also be analysed. Preliminary results indicate substantial shifts between the four stages at which $\mathrm{Q}$ sorts were administered. Notable shifts included an increase in the degree to which participants had a positive appraisal of key aspects of Australian democracy (Factor C). This shift occurred during the Canberra meeting. At the same time there was an increase in a commitment to the basic idea of citizen empowerment in politics (Factor D). Correspondingly, the degree of disaffection seemed to fall during the main meeting, after rising during the lead-up (Factor B). 


\section{CHANGES TO AGREEMENT WITH POSITIONS}

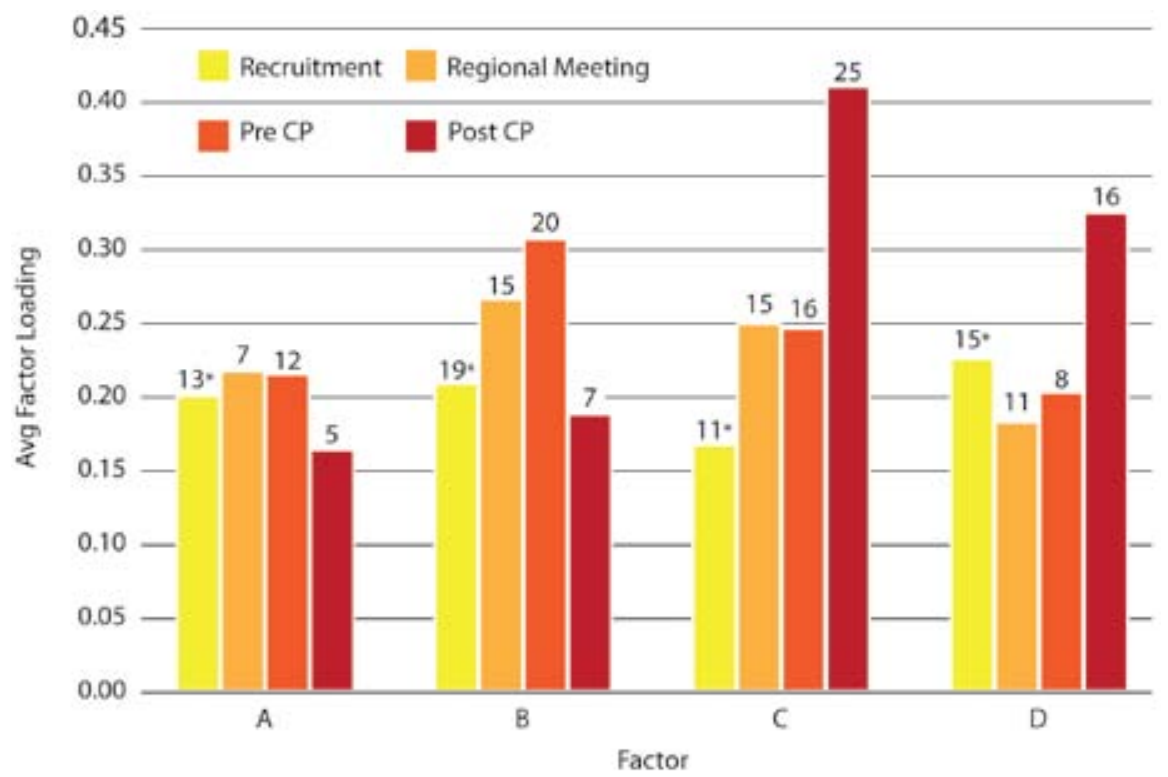

Another researcher is applying techniques of narrative inquiry to explore how deliberation can be viewed as an unfolding group story, demonstrating that deliberation is a collaborative rather than competitive endeavour. Many participants shifted in their social behaviour and style of talk, showing that they learned something about deliberation.

Because 23 tables were audio-recorded in parallel, the effects of different facilitation approaches can be compared, giving a better understanding of the importance and impact of different facilitation styles. The findings from that analysis will inform the training of facilitators for future deliberative events.

The online deliberation platform that fed into the 2009 Citizens' Parliament was used effectively by participants. It demonstrated that online deliberation requires more than just threaded discussion forums. It showed that a phased procedure allowed participants to quickly collaborate, construct coherent preliminary proposals and mutually endorse them.

Using the conversation record, researchers will continue to analyse how ideas 'gained legs' around the room and transformed as they absorbed wider perspectives. The conversation analysis will also confirm the accuracy and completeness of the theme team, which worked under considerable pressure to aggregate comments during the event. 


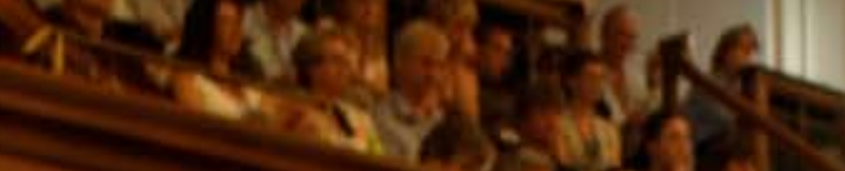




\section{LEARNINGS + PITFALLS}

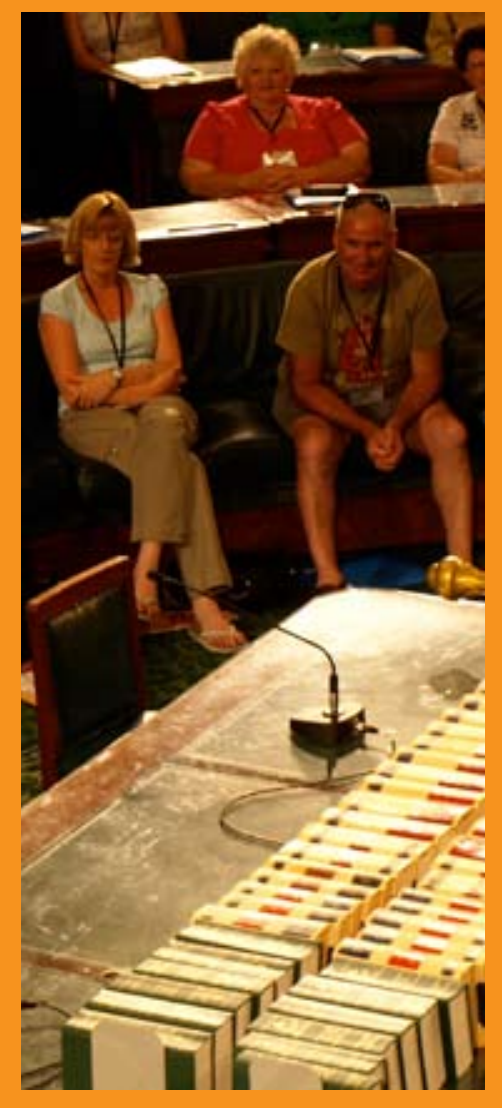

"I was never much into politics and I'm walking away from this weekend knowing a lot more about the system and what we can do to make it better." 


\section{LEARNINGS AND PITFALLS}

As the first citizens' parliament in Australia, one of the intentions of this event was to identify pitfalls and articulate learnings that could be applied to future events.

\subsection{GAINING SUPPORT OF GOVERNMENT}

The 2009 Citizens' Parliament was not convened by government, so no guarantee was offered to participants about the uptake of their recommendations. Senator Faulkner's opening remarks to the participants were encouraging but non-committal.

The Office of Prime Minister nominated a junior Cabinet Secretary to receive the recommendations on behalf of the government. Following the event, the organisers received a short letter of thanks from the Prime Minister's personal assistant, which stated:

"The Prime Minister appreciates the commitment made by the selected citizens and many volunteers who helped make the event such a success. The report represents a constructive contribution to the ongoing debate about our system of government and how it can serve Australia and its people better."

It is a disappointing response, coming in spite of the continued efforts of the convenors to engage the government and gain commitment to considering the outcomes.

Government will generally only pre-commit to outcomes of processes that have a clearly defined and well-accepted scope. For example, the British Columbia Citizens' Assembly for Electoral Reform was only concerned with determining the best form of parliamentary representation and voting. Careful and protracted effort may be required to convince the government to sponsor a deliberative event, especially if it appears to threaten the status quo. A government may also be more willing to undertake a citizens' parliament if it can put the recommendations to public referendum.

\subsection{ELECTRONIC COMMUNICATION AND SOCIAL MEDIA}

Facilities were in place for social media engagement, but no campaign of general public participation was launched for the 2009 Citizens' Parliament. The website's public forum received relatively little attention, and the Twitter identity gained more followers once the event was over.

Online parliamentarians were focused on the online deliberation platform and did not look elsewhere. After the event, a secure social networking site was set up for all the facilitators, and a second site for the participants. More than 80 participants subscribed, and there was an initial burst of activity which abated after the first few weeks.

In summary, there were few links between this deliberative process and participatory media - an area deserving of consideration in the future.

\subsection{PARTICIPANTS' RESPONSES}

Participants were not required to take any action after the 2009 Citizens' Parliament. However, a number took their own initiative to carry out 


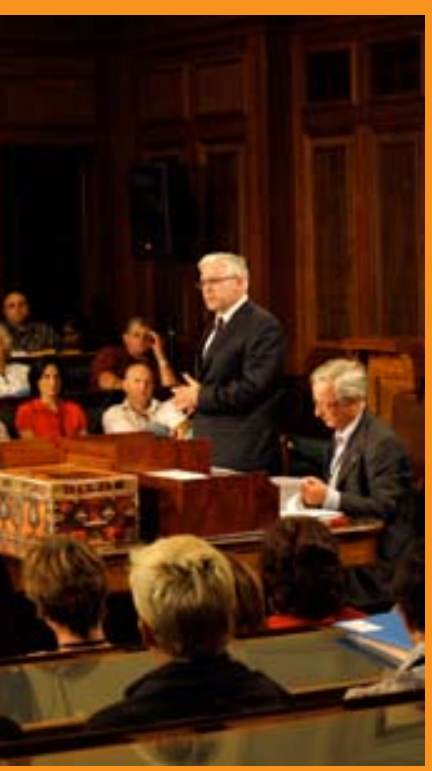

"The first two days I just sat there and didn't say a word - I just listened. Yesterday and today I've been able to speak up and it's been fantastic and I really want to take

this experience and turn it into something positive for myself and

I thank everybody so much."

Leah Goode, Citizen Parliamentarian.

After returning home, Leah Goode, the youngest citizen parliamentarian, made

contact with her local MP and took up a paid traineeship in the office of Adam Pederick. follow-up actions, such as contacting their local members to communicate the recommendations of the 2009 Citizens' Parliament, giving talks to community groups and schools, or contacting their local newspaper to run a story on what had happened.

Others have taken individual action as documented on their secure forum site and email messages. One participant who had initially expressed disinterest in politics is now working in an electoral office; another is exploring the possibility of running for parliament; yet another has introduced deliberative techniques into her junior school class room; and another into her workplace.

\subsection{COMMENTS FROM CITIZEN PARLIAMENTARIANS}

66 Success is 150 people coming together and demonstrating that we do understand what government is.?

66 Everybody is allowed to be heard. That's democracy.?

66 Good to be able to say we'd stuck to topic... without too many irrelevances.'

66 If you can't find a good politician, become one!'9

66 Half of the population would be keen to engage in this kind of activity.?

66 This model is about respect for people and ideas.?

66 Allows quick information gathering for a research project.'

66 It will be great to continue beyond the four days and I want to be part of it!?

66 We don't want the recommendations to end up sitting on a shelf.'?

66 This is so cool! Incredible learning opportunity! 9

66 My group grew up tremendously to support optional preferential voting.'?

66 Everybody has a different definition of democracy. 9 '

66 I had no idea about politics, I am very interested now. 9

66 The fresh ideas are important.?

66 Amazing - the way technology has worked.?

66 I have learned a lot how good it can be if we all have a go.'

66 A wonderful experience... Where are we going from here?... Can we keep the website to report back?'9

66 This adopted country of mine is so good to me and gave me the chance to speak out. Advance Australia fair!'?

66 Very honoured to be here... Fight and maintain our democracy. Keep it alive! 9

66 I see why politics and this process should be taught in school.? 


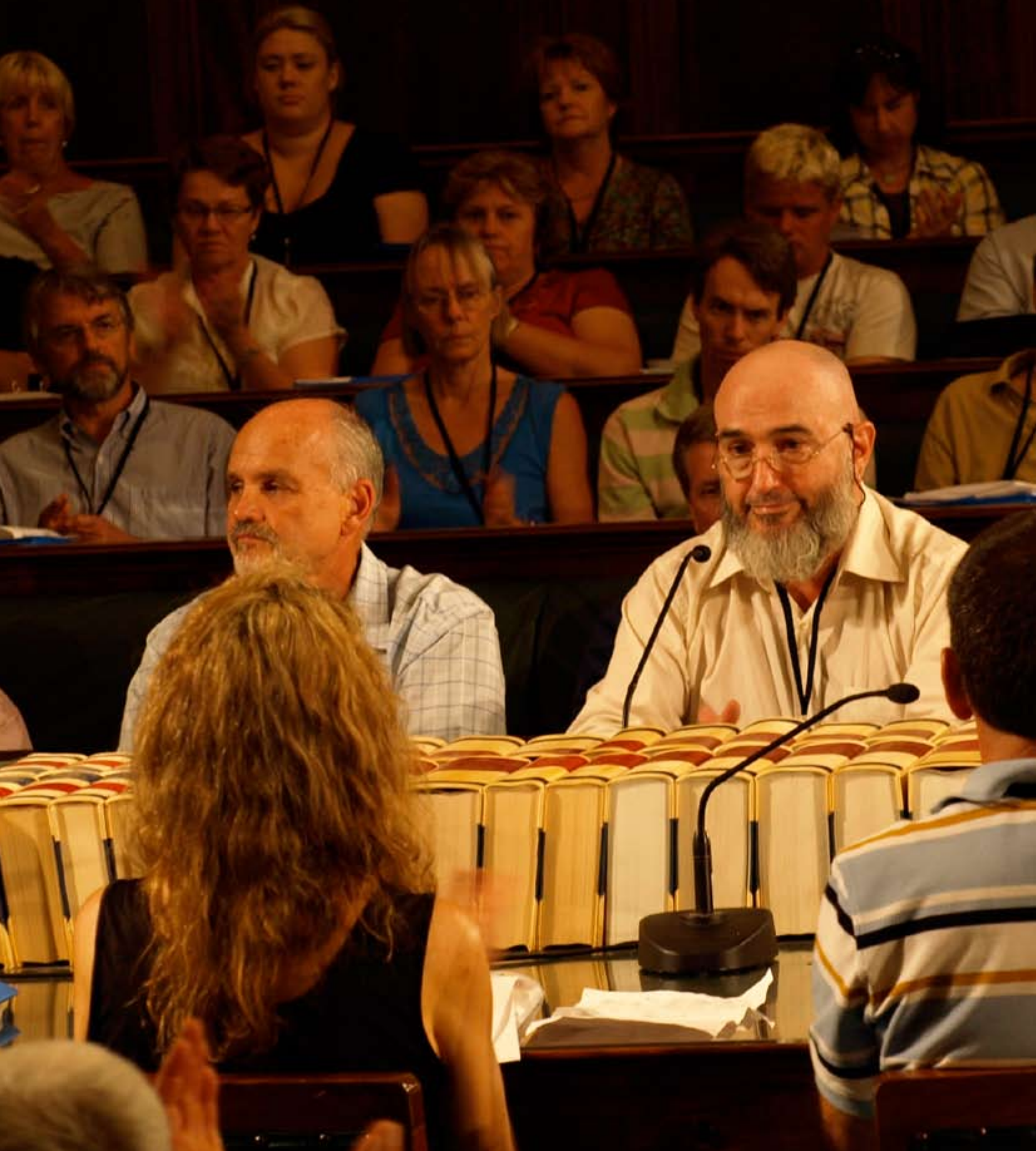




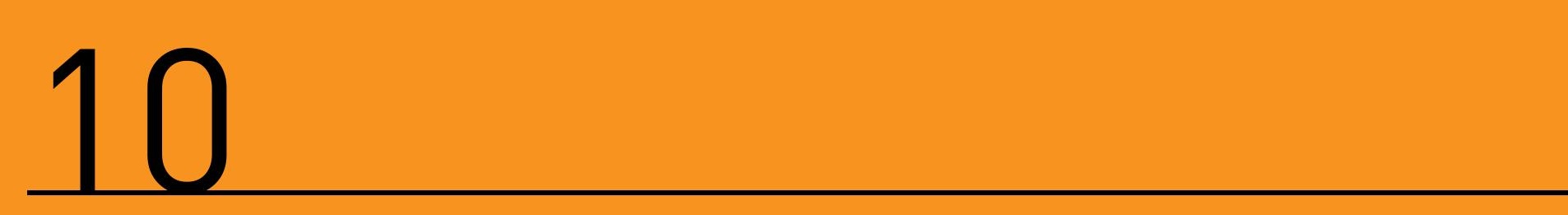

\section{THE FUTURE:}

POTENTIAL ROLES

FOR CITIZENS'

\section{PARLIAMENTS}

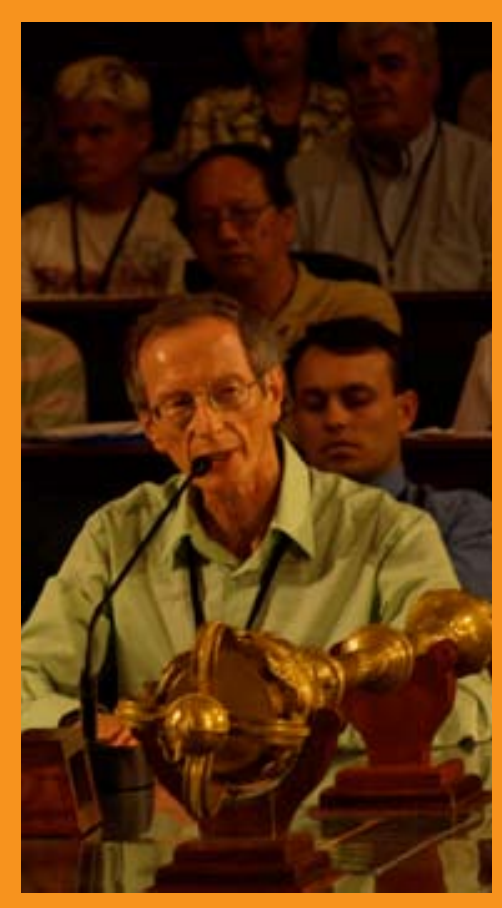

"What about a global citizens" parliament? There is a huge democractic deficit that a global citizens' parliament could help reduce. 
Convenor Professor John Dryzek made a speech to the Senate in April 2009 about the 2009 Citizens' Parliament. He made the following comments about the future of citizens' parliaments in Australia:

Historically, Australia pioneered votes for women and the secret ballot. For a long time in the United States, secret voting was known as the "Australian Ballot". Australia can now be at the forefront of democratic innovation, and the citizens' parliament is just one example. So where do we go next?

First, we might think about a formal role for institutions like the Citizens' Parliament. One possibility suggested by Ethan Leib in the United States in a book called Deliberative Democracy in America is that assemblies like this should constitute a fourth 'popular' branch of government, both scrutinising policies developed in the other branches, and generating proposals for them. The problem is the severe constitutional inertia that characterises the United States. Several years ago in the context of debates about reform of the House of Lords in the United Kingdom, the Demos think tank produced a paper suggesting the Lords be replaced by an assembly of randomly selected citizens. To me it is perfectly obvious that such an assembly would do a much better deliberative job than hereditary aristocrats (who have now gone) or the party hacks appointed for life (who have replaced them).

Applying this idea to Australia, Queensland is currently lacking an upper house, and so I commend this idea to Queensland (as well as Nebraska and New Zealand, similarly lacking). We need to create space for more deliberation in our politics. A citizens' parliament could be one component of a broader deliberative system.

What about a global citizens' parliament? A lot of political authority is now exercised at the global level; but there is a huge democratic deficit there that a global citizens' parliament could help reduce. A global citizens' parliament organised by random selection would actually be much more feasible than one organised by election. Random selection is much cheaper. The other key actors in establishing a global citizens' parliament would be the United Nations and the United States. The UN would not be a problem. And things look promising in the United States. The Deliberative Democracy Consortium in the United States now has access to the Obama White House. At the moment they are only discussing ways to invigorate deliberative citizen participation in the United States; but I also hope my American colleagues might be interested in going global.

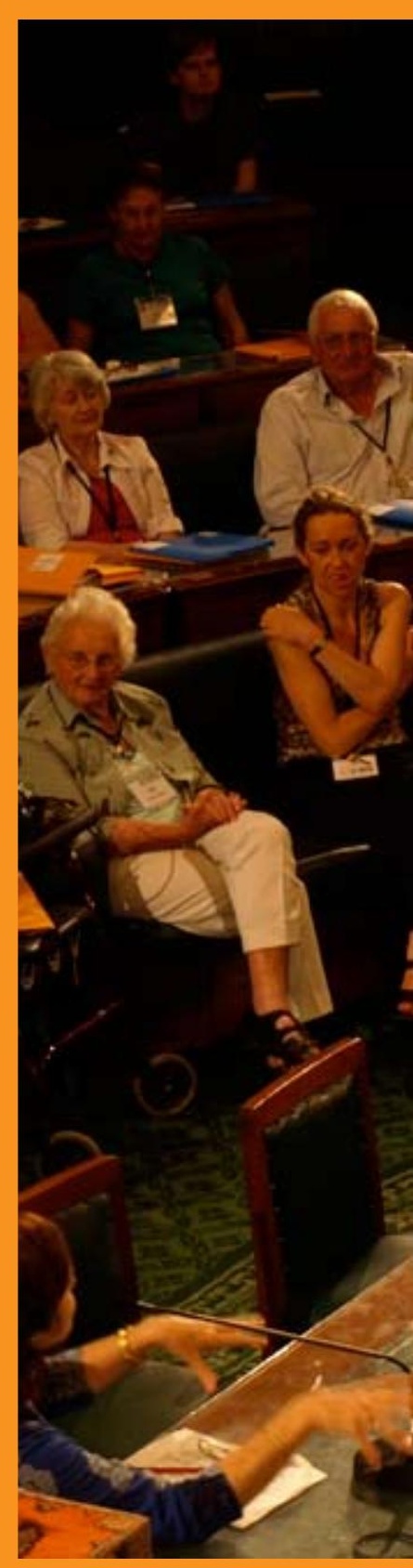




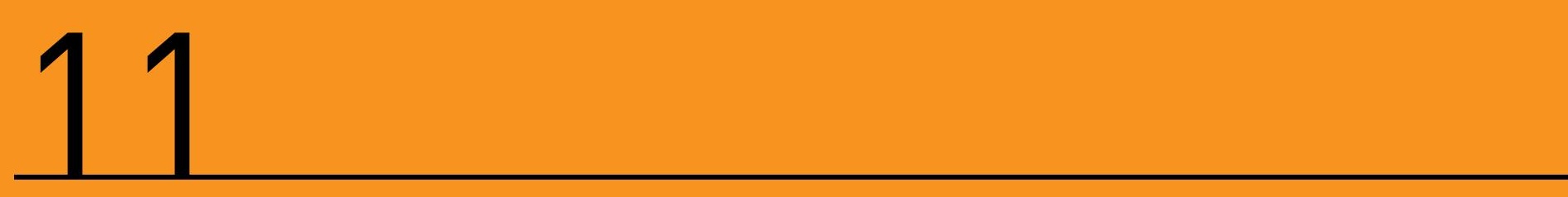

THE 2009 CITIZENS'

\section{PARLIAMENT \\ CONVENORS}

"I would like to acknowledge all the people who put so much time and energy into making it happen. Close to 200 people worked on the project, along with our 150 citizen participants." 
In 2004 Luca founded the community-based citizens' organisation, newDemocracy Foundation Limited. His writing and presentations on the subject have been the catalyst for a diverse group of academics, politicians, and business leaders to come together in the interests of democratic political reform. He has organised public forums and seminars involving leading academics and former politicians, providing intellectual leadership in thinking about alternative political systems and citizen engagement in the democratic process.

\section{Associate Professor Lyn Carson}

\section{Chief Investigator University of Sydney}

Associate Professor Lyn Carson works at the University of Sydney with the United States Studies Centre. She teaches courses about public involvement in decision-making, and conducts local and global research into deliberative innovations. Dr Carson has written handbooks on community engagement and many articles and book chapters on public participation.

\section{Professor John Dryzek}

\section{Chief Investigator Australian National University}

John is Professor of Political Science and Australian Research Council Federation Fellow in the Research School of Social Sciences, Australian National University. He is a Fellow of the Academy of Social Sciences in Australia, former Head of the Departments of Political Science at the Universities of Oregon and Melbourne and the Social and Political Theory program at ANU, and former editor of the Australian Journal of Political Science. Working in both political theory and empirical social science, he is best known for his contributions in the areas of democratic theory and practice and environmental politics.

\section{Professor Janette Hartz-Karp}

\section{Chief Investigator, Curtin University}

Janette Hartz-Karp is Professor of Sustainability at the Curtin University Sustainability Policy (CUSP) Institute at Curtin University in Perth. For 4.5 years as community engagement consultant to the Minister and the Western Australian Department for Planning and Infrastructure, Janette's task was to find innovative ways to achieve joint decision making with the community, pioneering deliberative democracy. Janette has continued this work with local and state governments across Australia and overseas. 


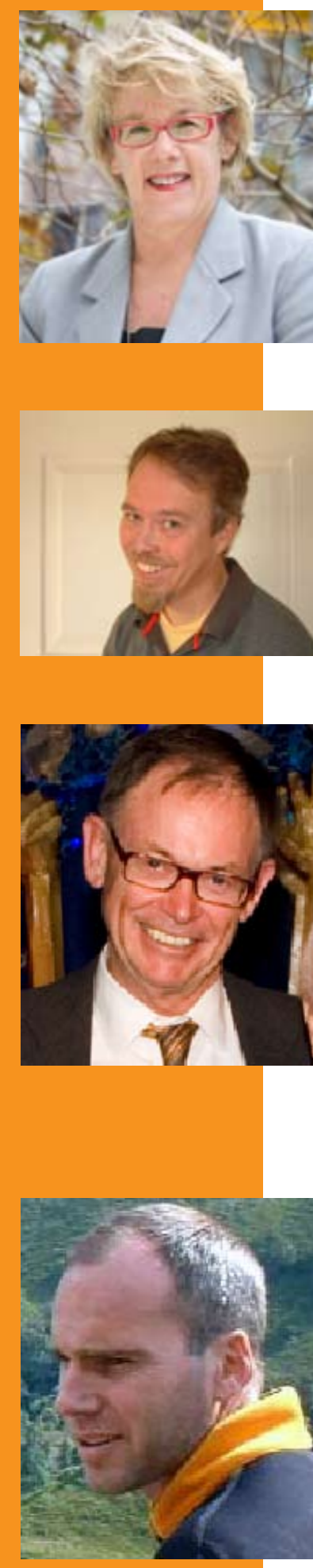

\section{Kathy Jones}

\section{newDemocracy Director}

Kathy Jones, Principal of communications consultancy KJA Strategic Communications and Project Management, is an expert in issues management and consultation. Kathy joined newDemocracy as a Director in 2006 and is responsible for newDemocracy Foundation's communications strategy. Kathy was a member of the Citizens' Parlimament project team and managed the regional media campaigns for each of the participants. During the event she managed the media team.

\section{Ron Lubensky}

Ron is a PhD candidate at The University of Sydney. His research examines the experience of deliberation by citizens participating in engagement processes about public policy, including face-to-face and online processes. Ron has had a 20-year career in ICT and online learning resource (e-learning) development and collaborative learning for adults working in corporate and public institutions.

\section{Professor lan Marsh newDemocracy Director}

Ian Marsh is a professor at the Australian Innovation Research Centre. Prior to this he held the Australia and New Zealand School of Government Chair of Public Management at the University of Sydney. He has also held appointments with the Research School of Social Sciences, Australian National University and the Australian Graduate School of Management, University of NSW. He graduated with a PhD in political science from Harvard University in 1985. Other affiliations have included Research Director for the Committee for the Economic Development of Australia, and the Australian Business Foundation.

\section{Simon Niemeyer}

Simon is a Research Fellow at the Research School of Social Sciences, Australian National University. He is examining the processes of preference transformation of individuals participating in democratic discourse. Apart from the ANU, he has conducted past research at the University of Cambridge, University of Birmingham and CSIRO (Australia). He has collaborated with a large number of researchers from Australia, USA and Europe. 


\section{2 \\ RESOURCES}

www.citizensparliament.org.au

The public website of the 2009 Citizens' Parliament.

\section{www.newdemocracy.com.au}

Website of newDemocracy (formerly newRepublic), a not-for-profit organisation that promotes, encourages and provides opportunities for discussion about the need for political reform.

\section{www.activedemocracy.net}

Website of Associate Professor Lyn Carson, containing information to enhance citizens' involvement in the activities of local, state or federal government.

\section{www.21 stcenturydialogue.com}

Website of 21st Century Dialogue, an Australian business led by Janette HartzKarp, specialising in community engagement that maximises opportunities for inclusiveness and deliberation.

\section{www.americaspeaks.org}

Website of AmericaSpeaks, which has the mission of reinvigorating American Democracy by engaging citizens in public decision-making.

\section{www.theworldcafe.com}

Website of the World Café, an innovative and simple methodology for hosting conversations about questions that matter.

\section{www.civicevolution.org}

Website of CivicEvolution, which provides free support for citizens engaged in community problem solving.

\section{www.thataway.org}

Website of the National Coalition for Dialogue and Deliberation, an online hub for those dedicated to solving tough problems with honest talk, quality thinking and collaborative action.

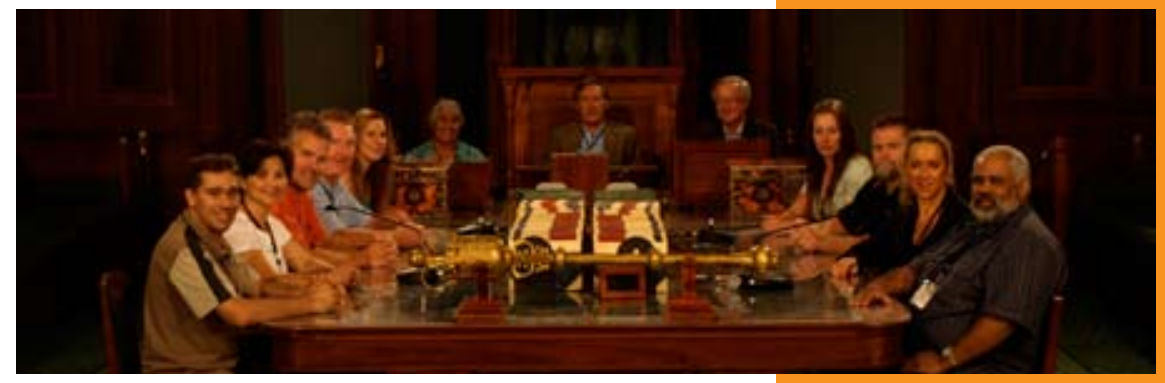




\section{3 \\ APPENDICES}

The 16 appendices to this handbook can be downloaded singly or as one large document from the newDemocracy website at

www.newdemocracy.com.au

The appendices are:

1. Deliberative democracy topic sheet.

2. 2009 Citizens' Parliament goals.

3. Reference panel membership.

4. Ombudsman of the 2009 Citizens' Parliament.

5. Support team roles.

6. Notes for facilitators.

7. How citizens were randomly selected.

8. Invitation to participate.

9. Letter to randomly selected participants.

10. Media Release: NSW-ACT citizens prepare for Australia's first citizens' parliament.

11. Regional meeting agenda.

12. Online parliament home page.

13. Screenshot of online proposal development.

14. Summary of the 11 proposals which came out of the online parliament.

15. One full proposal showing problem recommendation and justification.

16. Citizens' parliament mini-agenda.

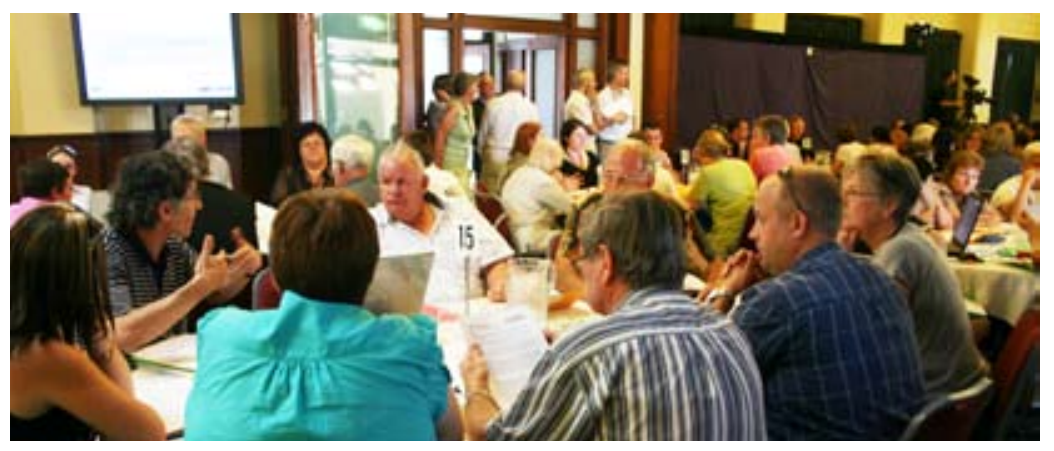




\section{ACKNOWLEDGEMENTS}

CO-CHAIRS Fred Chaney Lowitja O'Donoghue

CP OMBUDSMEN Phillip Hart Fiona Hollier

PANEL EXPERTS Professor Martin Krygier Anthony Green Professor John Warhurst Mark Yettica-Paulson Alannah MacTiernan MLA Simon Sheikh David Hammil

REFERENCE PANEL Fred Chaney Geoff Gallop Kath Fisher David Hammil David Yencken James Button Simon Sheikh Campbell Newman Warwick Smith Martin Krygier

Alannah MacTiernan

LEAD FACILITATORS Max Hardy Professor Janette Hartz-Karp

REPRESENTATIVES FROM GOVERNMENT Senator The Hon. John Faulkner (CP Opening)

Anthony Byrne MP (CP Closing)

CP PROJECT TEAM - SUPPORT Kath Fisher - Facilitator Coordinator Kathryn Kelly - ANU

Selen Ayirtman - ANU Elizabeth Cage - USyd Joan Donohue - newDemocracy

Vickianne Lane - newDemocracy Kaye Schumack - CP Documentary Team

John Pacitto - CP Documentary Team Brian Sullivan - Civic Evolution

Professor John Gastil - University of Washington

VOLUNTEERS, FACILITATORS AND CP SUPPORTERS The convenors and CP project team would like to extend their sincerest gratitude to the many volunteers and suppliers; without whose time, support and generosity, this event would not have been possible. 


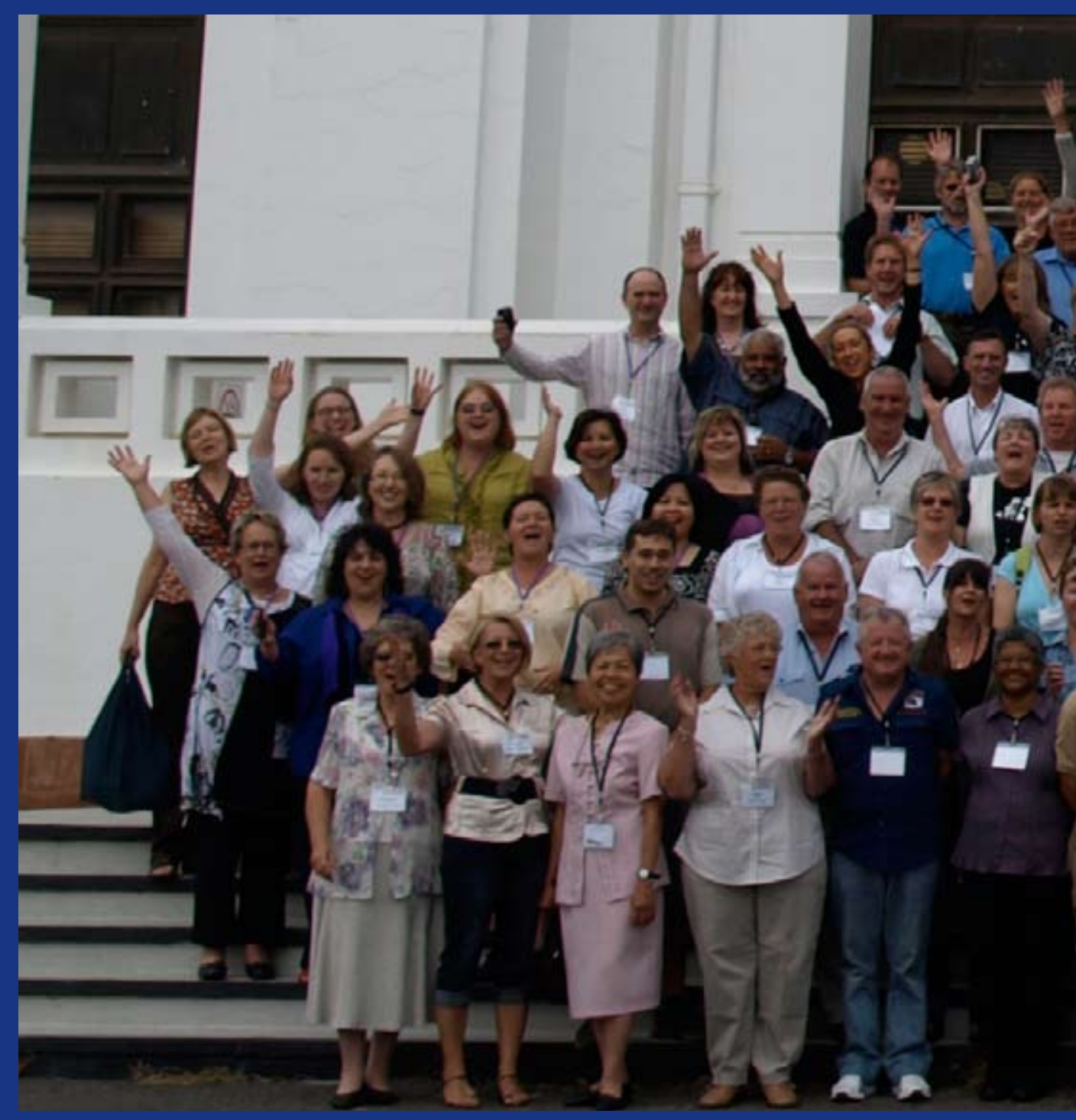

Parliament 